ERNEST $\square R L A N D Q$ LAWRENGE

BERKELEY NATIDNAL LABGRATGRY

\title{
Recommended Ventilation \\ Strategies for Energy-Efficient \\ Production Homes
}

Judy A. Roberson, Richard E. Brown, Jonathan G. Koomey, and Steve E. Greenberg

\author{
Environmental Energy \\ Technologies Division
}

RECEIVED

MAR 291999

December 1998 


\section{DISCLAIMER}

This document was prepared as an account of work sponsored by the United States Government. While this document is believed to contain correct information, neither the United States Government nor any agency thereof, nor The Regents of the University of California, nor any of their employees, makes any warranty, express or implied, or assumes any legal responsibility for the accuracy, completeness, or usefulness of any information, apparatus, product, or process disclosed, or represents that its use would not infringe privately owned rights. Reference herein to any specific commercial product, process, or service by its trade name, trademark, manufacturer, or otherwise, does not necessarily constitute or imply its endorsement, recommendation, or favoring by the United States Government or any agency thereof, or The Regents of the University of California. The views and opinions of authors expressed herein do not necessarily state or reflect those of the United States Government or any agency thereof, or The Regents of the University of California.

This report has been reproduced directly from the best available copy.

Available to DOE and DOE Contractors from the Office of Scientific and Technical Information

P.O. Box 62, Oak Ridge, TN 37831

Prices available from (615) 576-8401

Available to the public from the National Technical Information Service

U.S. Department of Commerce

5285 Port Royal Road, Springfield, VA 22161

Ernest Orlando Lawrence Berkeley National Laboratory is an equal opportunity employer. 


\section{DISCLAIMER}

Portions of this document may be illegible in electronic image products. Images are produced from the best available original document. 
LBNL-40378

UC-000

\title{
RECOMMENDED VENTILATION STRATEGIES FOR ENERGY-EFFICIENT PRODUCTION HOMES
}

\author{
Judy A. Roberson \\ Richard E. Brown \\ Jonathan G. Koomey \\ Steve E. Greenberg \\ Energy Analysis Department \\ Environmental Energy Technologies Division \\ Ernest Orlando Lawrence Berkeley National Laboratory \\ University of California \\ Berkeley CA 94720 , USA
}

This report can be found on the internet at:

http://enduse.lbl.gov/projects/ESVentilation

December 1998

The work described in this paper was supported by the U.S. Environmental Protection Agency, Office of Air and Radiation, Atmospheric Pollution Prevention Division through the U.S. Department of Energy under Contract No. DE-AC03-76SF00098. 


\begin{abstract}
This report evaluates residential ventilation systems for the U.S. Environmental Protection Agency's (EPA's) ENERGY STAR ${ }^{\circledR}$ Homes program and recommends mechanical ventilation strategies for new, low-infiltration, energy-efficient, single-family, ENERGY STAR production (site-built tract) homes in four climates: cold, mixed (cold and hot), hot humid, and hot arid.

Our group in the Energy Analysis Department at Lawrence Berkeley National Lab compared residential ventilation strategies in four climates according to three criteria: total annualized costs (the sum of annualized capital cost and annual operating cost), predominant indoor pressure induced by the ventilation system, and distribution of ventilation air within the home. The mechanical ventilation systems modeled deliver 0.35 air changes per hour continuously, regardless of actual infiltration or occupant window-opening behavior.
\end{abstract}

Based on the assumptions and analysis described in this report, we recommend independently ducted multi-port supply ventilation in all climates except cold because this strategy provides the safety and health benefits of positive indoor pressure as well as the ability to dehumidify and filter ventilation air. In cold climates, we recommend that multi-port supply ventilation be balanced by a single-port exhaust ventilation fan, and that builders offer balanced heatrecovery ventilation to buyers as an optional upgrade.

For builders who continue to install forced-air integrated supply ventilation, we recommend ensuring ducts are airtight or in conditioned space, installing a control that automatically operates the forced-air fan 15-20 minutes during each hour that the fan does not operate for heating or cooling, and offering ICM forced-air fans to home buyers as an upgrade. 
Abstract

Acronyms and Abbreviations

Definition of Terms

1. Introduction

2. Minimum Criteria 2

2.1. Ventilation Capacity 2

2.2. Continuous Operation 4

2.3. Condensation in Exterior Walls 4

3. Evaluation Criteria 4

3.1. Total Annualized Costs 5

3.2. Distribution Effectiveness

3.3. Indoor Pressure 5

4. Types of Ventilation Systems, their Advantages and Limitations 6

4.1. Exhaust Ventilation 6

$\begin{array}{lr}\text { 4.2. Supply Ventilation } & 10\end{array}$

4.3. Balanced Ventilation 15

5. Evaluation of Ventilation Systems

$\begin{array}{ll}\text { 5.1. Ventilation Costs } & 17\end{array}$

5.2. Ranking Ventilation Systems by Cost and Effectiveness 25

$\begin{array}{lr}\text { 6. Dehumidification } & 27\end{array}$

$\begin{array}{lr}\text { 7. Discussion } & 27\end{array}$

8. Recommendations $\quad 28$

Appendix A. When Is Continuous Depressurization of Homes Safe? 31

Appendix B. Itemized Capital Costs 33

Appendix C. Itemized Operating and Total Annual Costs 35

$\begin{array}{ll}\text { Appendix D. Infiltration as Ventilation } & 37\end{array}$

Appendix E. Dehumidification of Ventilation Air 39

$\begin{array}{ll}\text { E.1. Ventilation Latent Loads } & 39\end{array}$

$\begin{array}{ll}\text { E.2. Air Conditioning } & 40\end{array}$

E.3. Dehumidifying Supply Ventilation 41

E.4. Energy-Recovery Ventilation 41

Acknowledgments $\quad 43$

$\begin{array}{lr}\text { References } & 45\end{array}$ 
Table 1. Ventilation Systems Evaluated $\quad 7$

Table 2. Summary of Capital Costs $\quad 17$

Table 3. Energy Star Home Modeling Assumptions 18

Table 4. Total Air-Change Rates 19

Table 5. Fuel Prices and Space Conditioning Equipment Efficiency 19

Table 6. Summary of Ventilation Annual Operating Costs 20

Table 7. Scoring Method 25

Table 8. Ventilation System Scores $\quad 26$

Table 9. Summary of Ventilation Recommendations 29

Table D-1. Frequency of Under-Ventilation $\quad 37$

Table E-1. Latent and Sensible Loads of Ventilation Air 39

List of Figures $\quad$ page

Figure 1. Central Single-Port Exhaust Ventilation $\quad 8$

Figure 2. Multi-port Exhaust Ventilation 9

Figure 3. Forced-Air Supply Ventilation $\quad 12$

Figure 4. Multi-Port Supply Ventilation 14

Figure 5. Balanced Heat-recovery Ventilation 16

Figure 6. Ventilation Costs in Boston Homes with Gas Furnace/AC 21

Figure 7. Ventilation Costs in Wash DC Homes with Gas Furnace/AC 22

Figure 8. Ventilation Costs in Wash DC Homes with Electric Heat Pump 22

Figure 9. Ventilation Costs in Houston Homes with Gas Furnace/AC 23

Figure 10. Ventilation Costs in Houston Homes with Electric Heat Pump 23

Figure 11. Ventilation Costs in Phoenix Homes with Gas Furnace/AC 24

Figure 12. Ventilation Costs in Phoenix Homes with Electric Heat Pump 24 


\section{Acronyms and Abbreviations}

\begin{tabular}{|c|c|}
\hline $\mathrm{AC}$ & air conditioning \\
\hline $\mathrm{ACCA}$ & Air Conditioning Contractors of America \\
\hline $\mathrm{AC} / \mathrm{h}$ & air changes per hour \\
\hline AFUE & annual fuel utilization efficiency \\
\hline ASHRAE & $\begin{array}{l}\text { American Society of Heating, Refrigerating } \\
\text { and Air-Conditioning Engineers }\end{array}$ \\
\hline COP & coefficient of performance \\
\hline DSVU & dehumidifying supply ventilation unit \\
\hline $\mathrm{ECM}$ & electronically commutated motor \\
\hline EHP & electric heat pump \\
\hline ERV & energy-recovery (sensible and latent heat-recovery) ventilation unit \\
\hline FAC & gas furnace with central air conditioning \\
\hline FSEC & Florida Solar Energy Center \\
\hline HERS & Home Energy Rating System \\
\hline HRV & (sensible) heat-recovery ventilation unit \\
\hline $\mathrm{ICM}$ & integrated-control motor (all ICMs are also ECMs) \\
\hline LBNL & Lawrence Berkeley National Laboratory (formerly LBL) \\
\hline PSC & permanent split capacitor (motor) \\
\hline SEER & seasonal energy-efficiency ratio \\
\hline TMY & typical meteorological year \\
\hline
\end{tabular}




\section{Definition of Terms as they are used in this report}

balanced ventilation

energy-recovery ventilation

heat-recovery ventilation

\section{distribution}

circulation

delivery

duct

ductwork

exhaust ducts

supply ducts

outside-air duct

ventilation ducts .

exhaust ventilation

multi-port exhaust

passive vent

single-port exhaust

bath exhaust

central exhaust

fan

forced-air fan

local exhaust fan

ventilation fan (exhaust or supply)

port (exhaust or supply)

supply ventilation

forced-air supply

multi-port supply

ventilation

continual ventilation

continuous ventilation

intermittent ventilation

mechanical ventilation

natural ventilation continuously exhausts and supplies air in a house transfers sensible and latent heat between air streams transfers sensible heat between air streams movement of air by mechanical means movement of air in response to a fan only movement of air by a fan through a system of ducts tubular or rectangular passage through which air flows a system of ducts and their accessories ducts through which air is exhausted from a house ducts through which air is delivered to a house duct leading from the outside to indoors ducts that distribute only ventilation air ventilates by continuously exhausting air from a house exhausts air from several locations small screened opening in an exterior wall exhausts air from a single location exhausts air from a bathroom exhausts air from a central location an electronic air-moving device intermittently distributes conditioned indoor air intermittently exhausts air from one room ventilates an entire house opening in a wall or ceiling that is ducted to a fan ventilates by continuously supplying air to a house delivers air through forced-air conditioning ductwork delivers air through ventilation-only ductwork the regular exchange of indoor with outdoor air, along with any air treatment (tempering, filtering) or distribution automatically operates at regular intervals automatically operates non-stop $(8,760 \mathrm{hrs}$ /year) operates under the control of occupants or a sensor exchanges air by using one or more ventilation fans exchanges air by infiltration or open windows 


\section{Introduction}

As awareness and concern about global climate change increases, so does demand, in all parts of the country, for homes that require less fossil-fuel energy for space heating and cooling. The U.S. Environmental Protection Agency (EPA) ENERGY STAR Homes program encourages production (site-built tract) ${ }^{1}$ homebuilding companies to voluntarily exceed the Model Energy Code by minimizing envelope infiltration, installing better windows, increasing insulation levels, and properly sizing and installing efficient space heating and cooling equipment. Because lowinfiltration homes need mechanical ventilation, the ENERGY STAR Homes program asked our research group in the Energy Analysis Department at Lawrence Berkeley National Lab (LBNL) to recommend the most appropriate mechanical ventilation strategies for new, single-family ENERGY STAR homes in four climates: cold, mixed (hot and cold), hot humid, and hot arid.

Mechanical ventilation is uncommon in U.S. single-family homes because, until recently, it was thought that homes were leaky enough to provide adequate air exchange. However, building materials and practices have changed, leakage levels have decreased, and it has become obvious that ventilation is a residential design issue (ASHRAE 1997, Cummings and Moyer 1995). This report does not question whether mechanical ventilation is necessary; it assumes the need for mechanical ventilation, compares the cost and effectiveness of nine common ventilation systems, and recommends the most appropriate systems for production homes in four climates. Our analysis is based on computer simulations of ventilation systems in prototypical homes, and requires assumptions about climate, home characteristics, indoor pollutants, and occupants that do not necessarily apply to every situation. Our task is to provide general recommendations for ventilation of production homes in four climates, but we also provide information that enables contractors to choose the most suitable ventilation system for each set of circumstances.

Effective ventilation is important to home indoor air quality, occupant health and satisfaction, but mechanical ventilation adds to the cost of a new home. Production homes are designed and sold by large residential development companies (referred to in this report as "builders") whose profit margin depends on minimizing material and labor costs. Homes are actually constructed by subcontractors whose activity is coordinated by the builder. At each site, about 100 new homes are completed each year, i.e., an average of two homes per week. In general, subcontracting crews have very demanding work schedules and little or no training, and their supervisors emphasize productivity, not quality of work. Under these circumstances, ventilation systems need to be inexpensive for production builders and simple for subcontractors to install, without compromising homeowner's expectations of quality indoor air and low operating costs.

The short-term success of production home builders depends on sales, but their long-term success depends on the satisfaction of their customers. Production home buyers usually select among several floor plans and optional packages (upgraded cabinets, carpet, etc.), but decisions affecting home design are made by the builder. However, people who buy ENERGY STAR homes expect significantly lower utility bills than they would have in a typical new home, so the money saved on space conditioning should not be completely offset by the cost of operating a ventilation system. Furthermore, residents should be informed about their ventilation system but not aware of its operation because, unless ventilation is quiet and automatic, people will use it infrequently, or not at all, and poor air exchange could cause indoor air quality problems (Cameron 1997, ESB 1995a, ESB 1995b, Jackson 1993, Lubliner et al. 1997, Smith 1994, White 1996). By installing ventilation systems that are simple, quiet, and affordable for homeowners to use, production builders can improve customer satisfaction, reduce callbacks, and reduce their own exposure to liability related to poor indoor air quality.

Like many energy-efficient construction practices, residential ventilation was initially developed by builders in cold climates who realized that it costs less to mechanically ventilate and air-seal

\footnotetext{
${ }^{1}$ These recommendations are not intended for HUD-code manufactured homes.
} 
a home than to heat excess amounts of infiltration air (ESB 1995b). However, ventilation systems designed for homes in cold climates are not necessarily suitable for homes in the cooling-dominated sunbelt where most new homes are being built (EDU 1996c). Furthermore, tight homes and mechanical ventilation are relatively unknown in some parts of the south and southwest, where many residential contractors tend to equate "ventilation" with spot exhaust fans, which intermittently exhaust air from bathrooms and kitchens, or forced-air systems, which condition and recirculate indoor air. However, these familiar systems were not designed for ventilation, which is the regular exchange of indoor with outdoor air by a natural or mechanical system (Smith 1994). We evaluate these familiar systems that were adapted for home ventilation as well as less familiar systems that were designed for home ventilation.

\section{Minimum Criteria}

The ENERGY STAR Homes program requires that ventilation systems in ENERGY STAR homes meet the current U.S. ventilation standard, ASHRAE Standard 62-1989 (ASHRAE 1989). Ventilation systems that we evaluate also (1) provide 0.35 air changes per hour (AC/h) mechanical ventilation, (2) operate continuously, and (3) avoid chronic ventilation-related condensation in exterior walls. Ventilation systems that meet these criteria, which are discussed below, exceed the minimum requirements of ASHRAE- 62 by continuously providing the minimum air exchange specified by ASHRAE, regardless of infiltration or natural ventilation (Rashkin and Bloomfield-Resch 1997).

\subsection{Ventilation Capacity}

ASHRAE 62 says living areas need "0.35 air changes per hour but not less than $15 \mathrm{cfm}$ ( 7.5 $\mathrm{L} / \mathrm{s}$ ) per person." In other words, the standard is $0.35 \mathrm{AC} / \mathrm{h}$ or $15 \mathrm{cfm}$ per person, whichever is greater; the first guideline is based on building volume, the second on occupancy. When actual occupancy is unknown, as in the case of production homes under construction, occupancy is usually (but not always) assumed to be one more than the number of bedrooms, i.e., two occupants in the master bedroom and one in each additional bedroom ${ }^{2}$ (ASHRAE 1989, Tsongas 1993). We use the building volume guideline $(0.35 \mathrm{AC} / \mathrm{h})$, rather than assumed occupancy to determine minimum ventilation rates because the actual occupancy of any home will fluctuate over time. Also, the occupancy guideline is more appropriate when occupants are the principal pollutant sources, while the building volume guideline is more appropriate when the building itself is a significant source of air contaminants, as in most new production homes. However, this or any "standard" ventilation rate is necessarily somewhat arbitrary, controversial, and subject to change (Palmiter 1991).

ASHRAE's $0.35 \mathrm{AC} / \mathrm{h}$ is a minimum rate, and some consider $0.60 \mathrm{AC} / \mathrm{h}$ a practical upper limit for mechanical ventilation because as the ventilation rate increases, so do the conditioning costs. The State of Washington requires that new homes have mechanical ventilation systems capable of providing $0.35-0.50 \mathrm{AC} / \mathrm{h}$ and the Home Ventilating Institute (HVI) recommends a minimum of $0.50 \mathrm{AC} / \mathrm{h}$ mechanical ventilation. In Canada, the National Building Code requires a ventilation system capacity of at least $0.50 \mathrm{AC} / \mathrm{h}$ unless air is distributed throughout the house (Bower 1995, State of Washington 1998, Stevens 1996). Besides mechanical ventilation, infiltration and natural ventilation also contribute to the overall air exchange in a house, as discussed below. Our assumption that mechanical ventilation systems provide $0.35 \mathrm{AC} / \mathrm{h}$ results in total air change rates of $0.41-0.63 \mathrm{AC} / \mathrm{h}$ based on our modeling and depending on the climate and type of ventilation system; see Table 4 for details.

2 Consider a 1,500 square foot, three-bedroom home with $8^{\prime}$ ceilings. Using the occupancy guideline and assuming an occupancy of four, the ventilation rate would be (4 people $\times 15 \mathrm{cfm} /$ person =) $60 \mathrm{cfm}$. Using the building volume guideline, the ventilation rate would be $(0.35 \times(1500 \mathrm{sq} \mathrm{ft} \times 8 \mathrm{ft}) \div 60$ minutes $/ \mathrm{hr} \Rightarrow) 70 \mathrm{cfm}$. 


\subsubsection{Pollutant Sources}

The ventilation rate needed to maintain indoor air quality in any given home actually depends on the number, nature, and strength of indoor pollutants, which can be generally categorized as those generated by occupants and their activities, and those emanating from the building and its furnishings. The more pollutants there are in a home, the more ventilation is needed, and conversely, the fewer pollutants, the less ventilation is needed and the lower the operating costs.

Moisture and odors generated in bathrooms and kitchens should be exhausted by spot fans. ASHRAE 62 considers $0.35 \mathrm{AC} / \mathrm{h}$ ventilation the minimum rate necessary to control moisture and odor generated by occupants. However, this rate may not be adequate to control pollutants generated by additional occupants, such as pets or guests, or by household activities, such as smoking, cleaning, or hobbies that involve the use of chemicals. And $0.35 \mathrm{AC} / \mathrm{h}$ is not considered adequate to control "unusual" pollutants emanating from the building, including volatile organic compounds (VOCs) from interior finishes (carpet, paint, vinyl, etc), building materials (e.g., engineered wood), furniture, and furnishings (e.g., synthetic fabric) (ASHRAE 1989, Dumont and Makohon 1997, EDU 1993b, Hodgson 1997, Stevens 1996).

Building-related pollutants can be minimized through source control - the careful selection of building materials and furnishings combined with the education and cooperation of occupants. Source control, however, is not a component of the ENERGY STAR Homes program. Therefore, the design of ventilation systems for these homes needs to anticipate a large number of indoor pollutant sources - in effect, a worst-case scenario. Ventilation should be designed to control "unusual" pollutant sources, such as smoking and VOCs. In other words, ventilation systems should be designed to provide a minimum of $0.35 \mathrm{AC} / \mathrm{h}$ and have enough additional capacity so that residents can boost the ventilation rate during periods of higher pollutant loads (EDU 1993b, Hodgson 1997, Lstiburek 1995).

\subsubsection{Infiltration and Natural Ventilation}

The air exchange rate of a home is the sum of infiltration, natural ventilation (open windows), and mechanical ventilation. We do not consider average annual infiltration rates, as estimated by blower-door measurements, as contributing to the minimum $0.35 \mathrm{AC} / \mathrm{h}$ ventilation rate because actual infiltration varies widely according to the microclimate, weather, and season. Actual infiltration, which is driven by wind and stack effect, is lowest during mild weather and highest during winter and summer, so tight homes that rely on infiltration for air exchange will be underventilated in spring and fall and over ventilated during the heating and cooling seasons (Feustel et al. 1987). See Appendix D for further discussion of infiltration as ventilation.

Another reason to disregard infiltration is that mechanical ventilation is simpler for production builders to implement if the same ventilation system can be used in all homes of the same model; this is difficult if variations in leakage area among homes must be accounted for but very easy if these variations are ignored. Therefore, we assume that ventilation systems deliver the minimum ventilation rate of $0.35 \mathrm{AC} / \mathrm{h}$, with infiltration additional to mechanical ventilation.

Some designers assume that if people need ventilation, they should and will open their windows. Open windows can provide ventilation, and some people keep some windows open year-round. However, we cannot assume that everyone keeps windows open year-round. In fact, some people keep windows closed year-round for reasons that include noise, security, allergies, asthma, infirmity, and outdoor pollution. If indoor air quality of energy-efficient homes was dependent on windows, either indoor air quality or energy-efficiency would be compromised, depending on whether windows are closed or open during harsh weather. Residents should be able to open windows without turning their ventilation system off, and to close windows without having to remember to turn the ventilation system back on. We consider open windows (natural ventilation) supplemental to mechanical ventilation, and do not account for it in our evaluation. 


\subsection{Continuous Operation}

Homeowners should be informed about their ventilation system, but should not be aware of it. If residents have to think about turning their mechanical ventilation system on or off, they may deliberately or inadvertently turn it off and leave it off, which could lead to indoor air quality problems. Therefore, operation of residential ventilation systems should be automatic.

Ventilation rates are an average of air exchanges over some period of time (e.g., a day, or year). Ventilating at $0.35 \mathrm{AC} / \mathrm{h}$ for 24 hours a day and ventilating at $0.70 \mathrm{AC} / \mathrm{h}$ for 12 hours a day provide the same average ventilation rate, but these two ventilation operating schedules are not equally effective at controlling the level of indoor air pollutants to which residents are exposed. For ventilation systems with the same average ventilation rate, and for contaminants of a consistent source strength (e.g., VOCs from building materials and furnishings), continuous operation at a lower rate is more effective at controlling indoor pollutants than non-continuous operation at a higher rate (Fisk \& Turiel 1983, Hekmat et al 1986, Lubliner et al 1997, Palmiter \& Brown 1989). Therefore, operation of residential ventilation systems should be continuous.

Continuous ventilation is most effective at controlling indoor contaminants, but there is one situation in which continuous ventilation may not be advisable. Because of the relatively high cost of operating forced-air fans with standard permanent split-capacitor (PSC) motors, ventilation systems that rely on these fans are usually operated continually (at regular intervals), instead of continuously. One researcher estimates that operating forced-air systems continually (e.g., $20 \mathrm{~min} / \mathrm{hr}$ ) can save $60 \%$ of the cost of operating a PSC forced-air fan continuously (Rudd 1998b). Our evaluation assumes all ventilation systems, including those that use PSC forced-air fans, operate continuously; thus, all our operating costs reflect continuous operation.

\subsection{Condensation in Exterior Walls}

Ventilation-induced pressure can sometimes affect the long-term structural integrity of a home. Supply ventilation pushes indoor air out of a house through the exterior walls. In humid climates, this is an advantage because it helps prevent humid outdoor air from entering (Feustel et al. 1987). However, during the heating season in cold climates, moist indoor air moving through exterior walls can condense on surfaces in the wall that are below dew-point, e.g., the inside surface of exterior sheathing. If the wall has a vapor barrier on the exterior surface or if the heating season is prolonged, accumulated condensation in the wall cavity may eventually lead to rot of wooden framing members (Cummings and Moyer 1995, Gehring 1994). Similarly, negative indoor pressure pulls outdoor air into a home through exterior walls where, in hot humid weather, moisture condenses on the first cool (air conditioned) surface within the wall, e.g., the outside surface of interior sheathing. If there is a vapor barrier on the interior wall surface, the wall can't "dry to the inside" and accumulated moisture may lead to rot (EDU 1996b). Building scientists can anticipate and avoid these potential problems, but within the context of the ENERGY STAR homes program, supply ventilation (positive indoor pressure) should be avoided in cold climates and exhaust ventilation should be avoided in hot humid climates because, even with passive vents installed, exhaust ventilation pulls humid outdoor air into the house via infiltration, and condensation can eventually lead to rot (ESB 1995a). Condensation in exterior walls is not a concern in arid climates or with balanced ventilation.

\section{Evaluation Criteria}

Beyond the minimum criteria just described, ENERGY STAR home ventilation systems should also be simple and inexpensive for contractors to install, be simple and inexpensive for residents to operate, and distribute ventilation air effectively within the home. In addition, mechanical ventilation affects relative indoor pressure, which, in turn, can affect occupant safety and health. Therefore, our analysis includes these evaluation criteria: (1) total annualized cost (annualized capital cost + annual operating cost), (2) distribution effectiveness, and (3) predominant indoor pressure. The remainder of this section explains the nature and importance of these criteria. 


\subsection{Total Annualized Costs}

The total annualized cost of a ventilation system is the sum of its annualized capital cost and its annual operating cost. Annualized capital costs include installation costs (materials and labor) and the cost of periodic equipment replacement (maintenance) over the lifetime of the system; we use a lifetime of 20 years, based on the estimated life of its longest-lived component - ducts. Annual operating cost includes ventilation fan energy and the cost of tempering air introduced by mechanical ventilation, including any infiltration attributable to mechanical ventilation. See Section 5 for a detailed discussion of ventilation capital, operating, and total annualized costs.

\subsection{Distribution Effectiveness}

In his book Understanding Ventilation, John Bower says "Ventilation effectiveness has to do with how well a system removes stale air from where pollutants are produced and how well it introduces fresh air where people need it.... The more effective a ventilation system is, the less capacity it needs; therefore, it will be less costly to install and operate." Ventilation air is needed in all habitable rooms, particularly bedrooms, where (most) people spend most of their time (Bower 1996, EDU 1997a, ESB 1995b, Reardon 1995, Smith 1994). So it is not enough for air to enter the home; air must reach the people for whom it is intended. Our evaluation compares the ability of ventilation systems to distribute air throughout a home, which depends on the number and location of ventilation fans and whether ventilation airflow is ducted. Air moves in response to differences in temperature (i.e., natural convection) and differences in pressure, which are created by natural forces (e.g., wind and stack effect) and mechanical forces (e.g., operation of a fan) (Jackson 1993, Kesselring 1991). In this report, distribution describes movement of air in response to mechanical forces: circulation describes the distribution of air in response to a fan only, and delivery describes the distribution of air by a fan through a system of ducts. In general, exhaust ventilation systems rely on air circulation, and supply ventilation systems rely on air delivery.

\subsection{Indoor Pressure}

In addition to occupant-generated and building-related pollutants, the most dangerous potential pollutants are those that belong outdoors. Living spaces should be free of combustion products (e.g., carbon monoxide) and radon, which can endanger the safety and health of residents. When air is mechanically exhausted from a tight home, a negative pressure develops indoors; this depressurization can be a significant safety and health risk. Indoor pressure as low as -3 Pascals can cause backdrafting (i.e., flue gas reversal) of fireplaces and combustion appliances (e.g., gas or oil furnaces and water heaters). ${ }^{3}$ Depressurization can also pull auto exhaust from an attached garage, mold from an attic or crawlspace, and radon gas (if present in the ground under the house) into a home through holes or cracks in the foundation (ASHRAE 1989, Bower 1995, Brook 1996, EDU 1997c, Greiner 1997, Wilber and Cheple 1997). Appendix A outlines the conditions in which depressurization of a home is safe.

The best way to keep radon and combustion products out of a home is to eliminate or exhaust them at their source. Ideally, all combustion appliances and fireplaces would be sealed and isolated from living areas, all new homes in radon-prone areas would have a radon mitigation system installed at the time of construction, and people would never operate motor vehicles in an attached garage, especially if the garage door were closed. However, the EPA estimates that $20 \%$ of new homes have radon mitigation systems (Chen 1998), and the overwhelming majority of new production homes have a fireplace and/or attached garage. The ENERGY STAR Homes program recommends that fuel-fired furnaces and water heaters be sealed systems that are

3 Backdrafting of fireplaces can introduce carbon monoxide, smoke, and particulates into a home; backdrafting of gas or oil appliances can bring carbon monoxide and other combustion gases into a home and may cause flame roll-out. 
effectively isolated from habitable space; however, this is not a program requirement, and we do not assume the absence of natural-draft combustion appliances in these homes.

Ventilation systems that do not cause significant depressurization vary in their ability to buffer against negative indoor pressure caused by other forces. Common household appliances, such as kitchen range hoods and clothes dryers, have exhaust fans powerful enough (250-1,000 cfm) to significantly depressurize tight homes. Ventilation systems that pressurize homes help offset such temporary depressurization and help prevent outdoor pollutants (e.g., radon, smog) from entering a home. So, from a safety and health perspective, ventilation systems that do not depressurize homes are preferable to those that do, and ventilation systems that pressurize homes provide an advantage over those that do not, and our evaluation takes this into account.

\section{Types of Ventilation Systems, their Advantages and Limitations}

A basic home ventilation system consists of at least one fan, ductwork connecting the fan to the outside and/or living space, and controls. Fans used for ventilation should be quiet $(<1$ sone), designed for continuous operation and long life (at least $10 \mathrm{yrs}$ ), ${ }^{4}$ and as efficient as possible. Ideally, ventilation fans and ductwork should be located in conditioned space, and fans should be located so that they are easily accessible for regular maintenance ${ }^{5}$ (CHBA 1995). Ductwork used for ventilation should be UL181-rated and designed and installed according to Air Conditioning Contractors of America (ACCA) Manual D, with minimal duct length and resistance to airflow (ACCA 1995a). Suitable duct materials include rigid metal or 4-6" flexible duct; ducts outside conditioned space (and some inside, e.g., those connected to outside) should be insulated. Duct system design should account for actual internal system resistance. Ventilation system operation should be automatic and continuous; controls should include a low-high speed switch and programmable timer (ESB 1995b, Lstiburek 1995, Nelson 1998). If prevailing code requires a ventilation on/off switch, it should be located and clearly labeled in such a way that residents understand the consequences of, and are discouraged from turning their ventilation system off. 6 Every ventilation system should be commissioned after installation to verify that ventilation ducts are airtight and that the proper (design) airflow is actually delivered to and/or exhausted from each space under operating conditions. A Homeowner's Manual should provide detailed information about the home ventilation system's purpose, specifications, operation, and maintenance (Lubliner et al. 1997).

There are three basic types of residential ventilation systems: exhaust, supply, and balanced. Exhaust systems pull indoor air out of a house, supply systems push outdoor air into a house, and balanced systems exhaust and supply similar volumes of air. The variations, advantages, and limitations of each type are described below. Table 1 lists the ventilation systems evaluated. All systems include a programmable timer and switch.

\subsection{Exhaust Ventilation}

Fans that exhaust air from a building are the simplest type of mechanical ventilation system. Most building codes require a local (spot) exhaust fan or operable window in every bathroom. When installed properly and used appropriately by occupants, spot exhaust fans remove odor, moisture, and smoke from near their source before they mix with and contaminate indoor air. If properly designed, selected, and installed, exhaust fans can also effectively ventilate homes. Exhaust ventilation systems use a fan to continuously remove indoor air, which is replaced by outdoor air entering holes in the building, including vents and chimneys (i.e., backdrafting, which is dangerous), windows, and infiltration routes (EDU 1993a, Stevens 1996).

4 Fans located remotely do not need to be as quiet as those located near the living space.

5 Our evaluation assumes that ventilation ductwork is in conditioned space.

6 For example "This switch controls the ventilation system. It should be ON whenever the home is occupied." 


\section{Table 1. Ventilation Systems Evaluated}

\begin{tabular}{|c|c|}
\hline Exhaust Systems & Components: \\
\hline $\begin{array}{l}\text { 1. Upgraded bath exhaust } \\
\text { 2. Single-port (SP) exhaust } \\
\text { 3. Multi-port }(M P) \text { exhaust } \\
\\
\text { Supply Systems } \\
\end{array}$ & $\begin{array}{l}\text { Exhaust fan located in a bathroom, with passive vents } \\
\text { Exhaust fan located centrally, with passive vents } \\
\text { Exhaust fan ducted to bathrooms, with passive vents } \\
\text { Components: }\end{array}$ \\
\hline $\begin{array}{l}\text { 4. Forced-air (FA) supply } \\
\text { 5. ICM forced-air supply } \\
\text { 6. Multi-port (MP) supply } \\
\text { Balanced Systems } \\
\end{array}$ & $\begin{array}{l}\text { Forced-air fan with permanent split capacitor (PSC) motor, } \\
\text { outside-air duct with motorized damper } \\
\text { Forced-air fan with integrated-control motor (ICM), } \\
\text { outside-air duct with motorized damper } \\
\text { Supply fan ducted to bedrooms and living areas } \\
\text { Components: }\end{array}$ \\
\hline $\begin{array}{l}\text { 7. Balanced heat-recovery } \\
\text { 8. MP supply with SP exhaust } \\
\text { 9. FA supply with SP exhaust }\end{array}$ & $\begin{array}{l}\text { Heat-recovery ventilation unit ducted to and from rooms } \\
\text { Supply fan ducted to bedrooms and living areas, } \\
\text { with exhaust fan located centrally } \\
\text { PSC forced-air fan with PSC motor, outside-air duct with } \\
\text { motorized damper, exhaust fan located centrally }\end{array}$ \\
\hline
\end{tabular}

\subsubsection{Types of Exhaust Ventilation}

The variations of exhaust ventilation depend on the fan location and number of exhaust ports. One variation replaces a bath exhaust fan with an upgraded bath exhaust fan sized for the whole house. 7 Alternatively, the exhaust ventilation fan may be located centrally, e.g., in a hall. Both these systems exhaust from one location, so they are called single-port exhaust systems. Multi-port exhaust systems use one fan to exhaust from several ports; a remote fan is connected by 3-4" diameter ductwork to rooms where moisture and odors are generated, usually each bathroom and the laundry. Figure 1 illustrates a central single-port exhaust ventilation system.

Single-port exhaust is the same as upgraded bath exhaust except for the location of the fan, and the fact that upgraded bath exhaust saves the cost of one bathroom local exhaust fan. However, because of its central location, single-port exhaust usually provides better circulation. Multi-port exhaust costs more to install because of the ductwork involved but provides the best circulation of all the exhaust ventilation strategies because it exhausts from several rooms. Figure 2 illustrates multi-port exhaust ventilation.

\subsubsection{Circulation of Ventilation Air}

Exhaust ventilation depends on air moving freely between the house and the exhaust fan, but too often airflow is disrupted by closed interior doors. For example, with upgraded bath exhaust ventilation, flow of air to the exhaust fan can be disrupted when the bathroom door is closed and, if the fan is in a master bath, the master bedroom door can also disrupt flow of air.

Even with single-port exhaust, where the exhaust fan is centrally located in a hall or stairway, flow of air from any room can be disrupted by closing the door to that room. Unrestricted indoor airflow is essential to the effectiveness of any ventilation system and is especially important for forced-air system performance because air has to reach the forced-air return(s).

\footnotetext{
${ }^{7}$ In upgraded systems, a spot exhaust fan is replaced by a quiet, efficient exhaust fan with a PSC (or better) motor.
} 
Therefore, regardless of the ventilation system used, homebuilders should use at least one of the following measures to facilitate airflow: (1) install a forced-air return in every bedroom, (2) install through-wall transfer grilles between each bedroom and a hallway, or (3) undercut or louver interior doors (Brook 1996, Jackson 1993, Kesselring 1991).

\section{Figure 1. Central Single-Port Exhaust Ventilation}

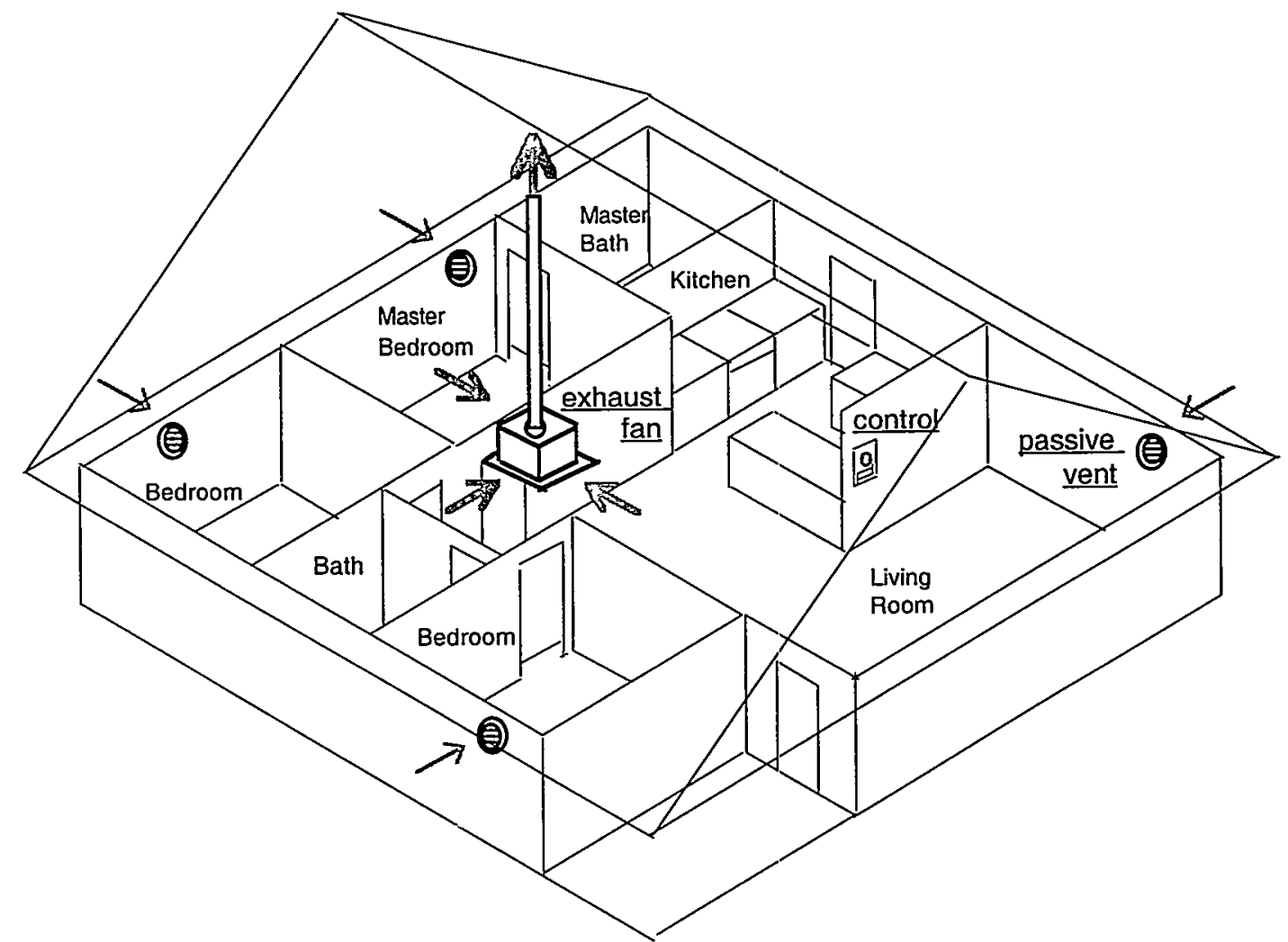

System Components:

1) quiet, efficient exhaust ventilation fan

2) several passive wall or window vents

3) programmable timer with speed switch
System Operation:

1) The exhaust ventilation fan operates continuously.

2) Spot fans exhaust air from kitchen and bathrooms.

3) Residents can temporarily boost the ventilation rate.

\subsubsection{Depressurization}

In tight homes, exhaust ventilation systems create some degree of negative indoor pressure; the degree of depressurization depends on how tight the home is and how strong the exhaust fan is. Tight homes can be significantly depressurized by operation of a kitchen range hood, clothes dryer, or forced-air system whose ductwork is outside conditioned space and has more supply than return duct leakage (ASHRAE 1989, Brook 1996, Cummings and Moyer 1995, Stevens 1996). However, if there is also a continuous exhaust ventilation system, depressurization will be more frequent, severe, and prolonged than if there is no exhaust ventilation fan. The extent to which any house is depressurized by an exhaust ventilation system, forced-air system, or large exhaust appliances (individually and in combination) can only be determined by diagnostic (pressure) testing of every ENERGY STAR home, which is strongly recommended (Bower 1995, ESB 1995b, Smith 1994, Stevens 1996). 
Figure 2. Multi-port Exhaust Ventilation

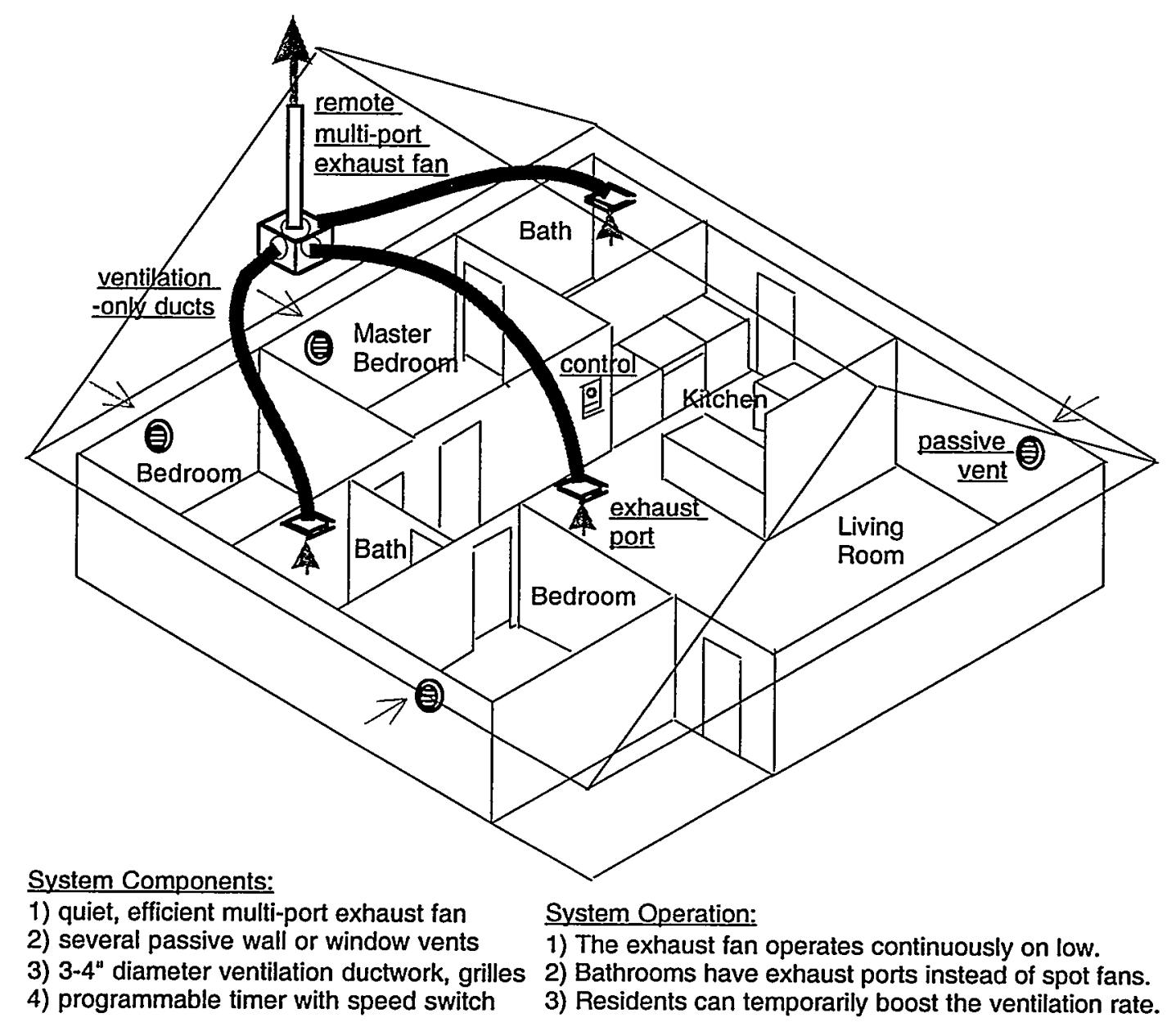

\subsubsection{Passive Vents}

Passive vents are small screened openings in exterior walls or windows that are designed to admit ventilation air (not combustion appliance makeup air) to a home in response to negative indoor pressure created by a continuous exhaust ventilation fan. They are designed for use in very small, tight homes in which depressurization has been determined not to be a safety and health risk; see Appendix A for an examination of conditions in which depressurization is safe.

Used properly, passive vents offer some control over the location of air entry into the home; usually, one vent is installed in each bedroom and living area. The amount of airflow through passive vents can be controlled (by adjusting the opening size), but the direction of airflow through the vents depends on differences in pressure within and outside the building. ${ }^{8}$ For passive vents to function as air inlets, the exhaust ventilation fan must maintain at least 10 Pascals negative indoor pressure. According to one major passive vent manufacturer, each passive vent (4-6 in ${ }^{2}$ net free area) ${ }^{9}$ admits $10-20 \mathrm{cfm}$ of outdoor air at andoor pressure of

\footnotetext{
${ }^{8}$ The term "passive inlet " is not used here because it misleadingly suggests that air moves in only one direction.

9 The Home Ventilating Institute (HVI) certifies vents for net free area, but at present, the HVI has not certified any passive vents that are designed for use in habitable areas.
} 
negative 10-20 Pascals. So, rather than relieving depressurization, passive vents actually require significant depressurization in order to be effective (Dietz 1998, Lubliner et al. 1997).

The role of passive vents in exhaust ventilation is understood in Scandinavia where homes are electrically heated, and depressurization is not considered a safety and health risk. In the U.S., however, passive vents are used in homes that are neither very tight nor small and that are not strongly depressurized by an exhaust ventilation fan. For example, the Washington State Ventilation and Indoor Air Quality (VIAQ) Code requires mechanical ventilation systems in new homes, and also requires that exhaust systems include "individual room outdoor air inlets" (i.e., passive vents), regardless of total leakage area or the degree of depressurization by the exhaust ventilation fan. The code requires that ventilation systems be capable of continuous operation but refers to them as "Intermittently Operated Whole House Ventilation Systems" (Lubliner 1998, State of Washington 1998).

Passive vents are not effective in larger, leakier homes because, unless the combined net free area of the passive vents is a significant portion of the total leakage area of a house, outdoor air is more likely to enter the house through random infiltration routes than through passive vents. Furthermore, if the exhaust ventilation fan does not sustain significant indoor depressurization, the direction of airflow through the vents will be determined by the interacting forces of wind, stack effect, large exhaust appliances, and forced-air system imbalances (Bower 1995, Brennan 1998, Lubliner et al. 1997, Palmiter 1991, Stevens 1996).

Consider a U.S. production home with a single-port exhaust ventilation system (e.g., $100 \mathrm{cfm}$ ); distribution of ventilation air depends on the centrally located exhaust ventilation fan being able to pull outdoor air into the home through the passive vents located in each bedroom and living area. However, if residents close their bedroom doors at night, the fan may not be able to pull air into the bedrooms through the vents, in which case the exhaust fan pulls air from other parts of the home, which may then become depressurized. Meanwhile, outdoor air is not coming in through the passive vents located in the bedrooms, so ventilation is not provided to sleeping occupants. Furthermore, any heated or cooled air delivered through bedroom supply registers will pressurize and leave the room through the passive vents, thus wasting the energy required to condition and distribute the air (Cummings and Moyer 1995, Gehring 1994). Measures that facilitate indoor airflow can minimize but don't eliminate this potential problem.

In two-story homes, this problem is exacerbated when cool air driven by stack effect enters the home on the lower level through passive vents or infiltration, and warm indoor air leaves through passive vents on the upper level; this provides ventilation and air circulation but at the expense of conditioning excess, uncontrolled airflow (Bower 1995, Reardon 1995). In cold climates, where winter stack effect is strongest, the loss of indoor air through passive vents in two-story houses may even be sufficient to depressurize the home (Steege 1998).

So, for exhaust ventilation to be effective, the exhaust ventilation fan must be powerful enough to maintain significant depressurization, which should be avoided in ENERGY STAR homes unless the conditions listed in Appendix $A$ have been evaluated and determined not to be a problem. And although passive vents are an important component of exhaust ventilation in tight homes, they do not prevent depressurization, ensure effective circulation of ventilation air, or necessarily protect the space-conditioning energy savings gained by tightening the envelope.

\subsection{Supply Ventilation}

Supply ventilation uses a fan to continuously supply outdoor air; spot fans intermittently exhaust indoor air and are manually controlled by occupants or automatically controlled by a dehumidistat. Fans used for exhaust can also be used for supply ventilation; the difference between "exhaust" and "supply" fans is orientation or direction of airflow with respect to the house. For supply ventilation to be effective, air must be delivered (by a fan via ducts) to several rooms, including each bedroom, and the resistance of the ducts must be accounted for. A basic supply ventilation system consists of a fan, ductwork connecting the fan to the outside 
and to several rooms, and controls; outdoor air may or may not be mixed with and tempered by indoor air before being delivered (Bower 1995, EDU 1998, Steege 1998).

\subsubsection{Air Filtration}

Supply fans make it possible to filter ventilation air, which is an important consideration for the growing number of people with asthma, allergies, and environmental sensitivities (American Lung Association et al. 1994, Gehring 1996, Ulness 1997). Supply systems that include an air filter must be designed to account for the added resistance of the filter and to allow easy replacement of the filter; occupants should be informed about the need to replace the air filter (Bower 1995).

\subsubsection{Pressurization}

A significant advantage of supply ventilation in homes is that it creates positive indoor pressure. When a supply fan delivers air to a tight house, the home becomes pressurized, which helps prevent outdoor pollutants (e.g., radon) from entering and buffers against depressurization, which, while still possible, will be less frequent, severe, or prolonged than without the supply fan (Bower 1995, Finley 1997, Gehring 1996, Lstiburek 1995).

\subsubsection{Forced-Air Supply}

As the demand for central air conditioning in U.S. homes has grown, forced-air systems have become standard in new homes in most climates. Therefore, when ventilation is called for, many residential contractors adapt the familiar forced-air conditioning systems for ventilation. To do so, contractors introduce outdoor air by installing an outside-air duct (6-8" diameter) that connects outdoors to the forced-air return. A motorized damper in the outside-air duct is adjusted once, at installation, to admit the design volume of ventilation air and is electronically controlled (by the forced-air fan control) to open whenever the forced-air fan runs; negative pressure in the duct pulls outdoor air into the forced-air return where it mixes with indoor air before being delivered. Forced-air supply is the cheapest ventilation system to install because the forced-air fan and ducts are already there. Figure 3 illustrates forced-air supply ventilation.

Forced-air supply provides ventilation only when the forced-air fan operates, and a forced-air fan usually runs only if the thermostat calls for heating or cooling, so, under normal conditions, a house with forced-air supply ventilation might not receive outdoor air for days, weeks, or months at a time. For forced-air supply to provide ventilation on a regular basis, the forced-air fan needs to operate on a regular basis, and, as noted above, this operation should be automatic. Fortunately, several manufacturers (including DuroDyne, Honeywell, and Tjernlund) and the Florida Solar Energy Center offer forced-air fan controls that automatically operate forced-air fans continually, at regular intervals, for ventilation (Jackson 1993, Rudd 1998a, Stevens 1996). Forced-air supply systems should include a control that automatically operates the fan at regular intervals and opens the outside-air damper when the fan is running.

Another disadvantage of forced-air supply systems, is that standard (PSC) forced-air fans are so noisy (as typically installed) and expensive to operate that residents may be reluctant to use the forced-air system for ventilation; however, unless tight homes receive ventilation, indoor air quality and health may be affected (ESB 1995b, Jackson 1993, Lubliner et al. 1997).

Yet another disadvantage of forced-air supply is that leaky return ducts in unconditioned spaces (e.g., an attic or crawlspace) can introduce mold, microbes, radon, and particulates to the home (Jackson 1993). Contamination of indoor air by return duct leakage is minimized if forced-air ducts are sealed, and it is eliminated if ducts are installed in conditioned space. ${ }^{10}$

10 To avoid potential backdrafting, return ducts located in conditioned space must also be sealed (White 1998). 


\section{Figure 3. Forced-Air Supply Ventilation}

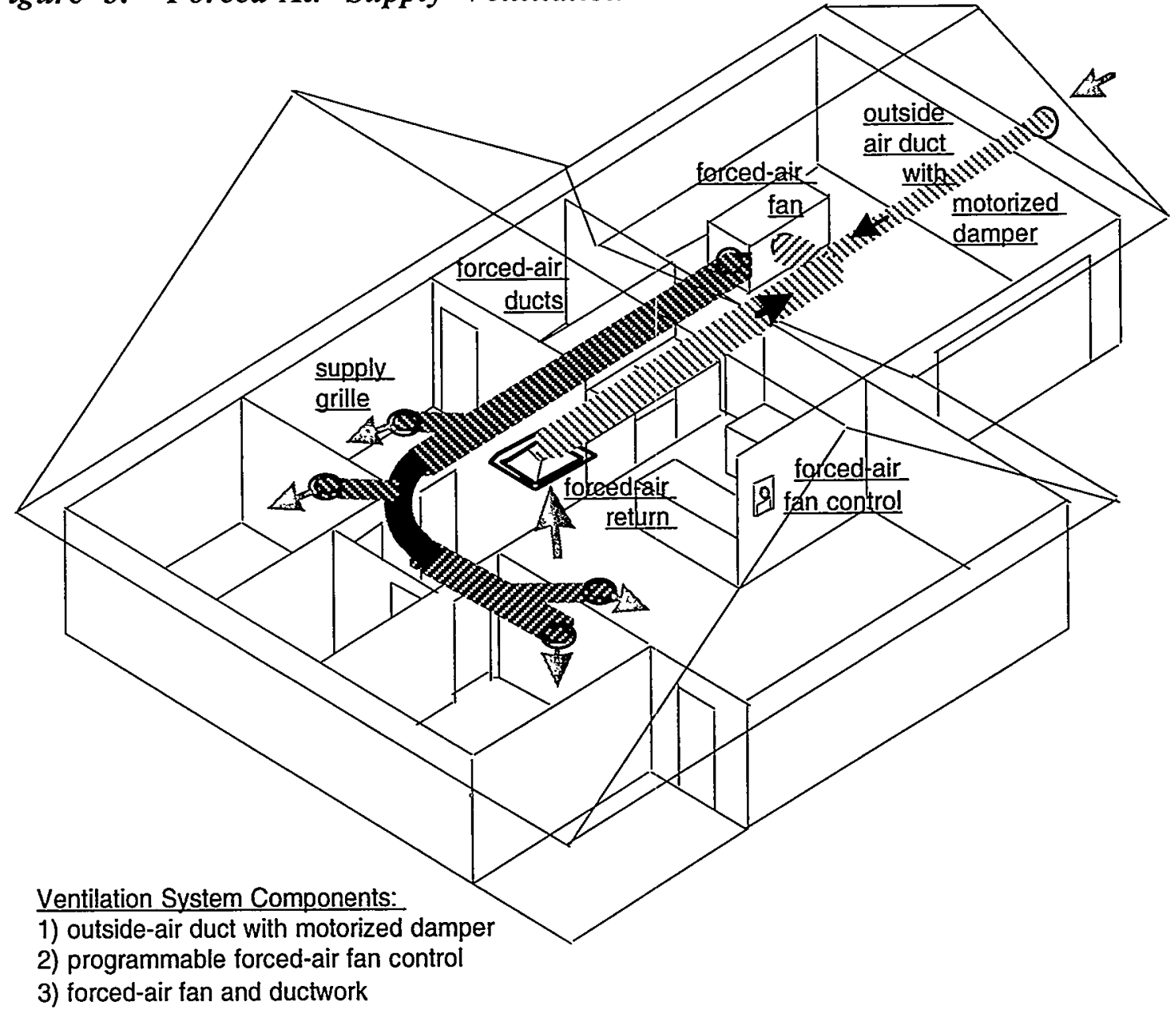

\section{Ventilation System Operation:}

1) Forced-air ducts are airtight and/or within conditioned space.

2) A motorized damper in the outside-air duct opens when the forced-air fan runs.

3) Controls automatically operate the forced-air fan at regular intervals for ventilation.

An alternative to operating a PSC forced-air fan continually for forced-air supply ventilation is to install another (quiet, efficient) supply fan to pull outdoor air into the outside air duct and distribute it through the forced-air ductwork. However, this additional fan increases system installation cost, thus offsetting the only real advantage of forced-air supply. Also, unless this fan uses much less energy than a forced-air fan, it may not reduce operating costs significantly.

\subsubsection{ICM Forced-Air Supply}

Another way to reduce forced-air supply operating costs is to use variable-speed forced-air fans with integrated-control motors (ICM), 11 which currently cost $\sim \$ 1,000$ more than standard builder-model fans but operate more efficiently over a wide range of speeds. PSC forced-air fans consume almost the same watts at high speed (e.g., 1,200 cfm for cooling) as they do at their lowest speed (e.g., $900 \mathrm{cfm}$ for heating), but an ICM fan that uses $300 \mathrm{~W}$ at 1,200 cfm uses

11 Variable-speed electronically-commutated motors (ECMs) are now manufactured with controls in the motor, so they are called integrated-control motors (ICMs) (Mills 1996). 
only $\sim 80 \mathrm{~W}$ at $600 \mathrm{cfm}$ (EDU 1995a). ICM forced-air fans are sometimes used to continuously recirculate indoor air, but they can also be used to provide continuous ventilation. Therefore, we evaluated ICM forced-air supply ventilation.

Whether a fan operating at low speed (say, $600 \mathrm{cfm}$ ) can distribute ventilation air through ducts designed for a much larger (say, 1,200 cfm) volume of air depends on the quality of the duct system. Each room should receive half the air at a fan speed of $600 \mathrm{cfm}$ as it receives at 1,200 $\mathrm{cfm}$ (assuming no duct leakage), but the proportion of air each room actually receives depends on how well the ducts are designed and installed. In other words, a forced-air system distributes ventilation air as well (or as poorly) as it distributes conditioned air (Archer 1998). This means that a forced-air (or any other) fan operating on low speed cannot distribute ventilation air evenly throughout the home unless the home also has an exemplary forced-air duct system.

Using ICM fans for ventilation raises the question of how ventilation rate varies with fan speed. Duct pressure is proportional to the square of airflow velocity, so there is one-fourth the duct pressure available at a fan speed of $600 \mathrm{cfm}$ as is available at a fan speed of $1,200 \mathrm{cfm}$. Therefore, if the damper in the outside-air duct is adjusted to admit, say, $100 \mathrm{cfm}$ of outdoor air when the ICM fan operates at $1200 \mathrm{cfm}$, how much air is admitted when the fan runs at 600 $\mathrm{cfm}$ ? The answer is probably unique to each installation and is definitely beyond the scope of this report. However, contractors who intend to use ICM forced-air fans for ventilation should be aware that if the damper in the outside-air duct is adjusted to admit the ventilation design volume (in $\mathrm{cfm}$ ) of outside air when the forced-air fan runs at high (cooling) speed, then the home will be underventilated when the fan runs at low speed for ventilation. Similarly, if the damper is adjusted to admit the ventilation $\mathrm{cfm}$ when the forced-air fan runs at low (ventilation) speed, the house will be over ventilated when the fan runs at high speed, with a corresponding energy penalty (increased operating cost) for tempering the additional air (Archer 1998).

\subsubsection{Multi-Port Supply}

Supply ventilation offers the advantages of positive pressure, ducted delivery of outdoor air, and the ability to filter and dehumidify incoming air. It is noteworthy that the prevalence of forced-air supply systems among homes with mechanical ventilation is attributable not to these advantages, but to the fact that forced-air supply ventilation has the lowest installation cost. However, considering the high operating cost, potential noise, drafts, and occupant dissatisfaction associated with operating a forced-air system for ventilation, it is important to realize that the benefits of supply ventilation can be achieved without the disadvantages of forced-air integration by using a quiet, efficient supply ventilation fan that continuously delivers outdoor air through ventilation-only (i.e., not forced-air) ductwork.

A multi-port supply ventilation system consists of an appropriately sized supply fan, ventilation supply ducts, and controls; outdoor air is delivered directly to bedrooms and living areas where residents spend the most time. Because ventilation airflow is about $10 \%$ of conditioned airflow, ventilation-only ducts are smaller than forced-air ducts, and easier to fit in conditioned space. Unlike exhaust systems, multi-port supply delivers outdoor air directly to bedrooms and living areas, so these rooms receive continuous ventilation regardless of how well indoor air circulates. Figure 4 illustrates multi-port supply ventilation.

\subsubsection{Supply Ventilation Duct Efficiency}

Location of forced-air or multi-port supply ventilation ducts affects ventilation system operating costs. Duct systems should be (and this report assumes they are) properly designed and installed, airtight, and insulated. Even so, heat will be conducted between ducts and their surrounding space when the temperature of air in the ducts is different from the temperature of the surrounding space. Our operating cost estimates account for the energy required to condition ventilation air brought directly into the house, but they do not account for tempering energy needed to offset conductive heat gains and losses of ventilation supply ducts located in unconditioned space. Our analysis assumes supply ducts are within conditioned space, but the 
cost of tempering ventilation air can change significantly if ducts are in a basement, crawlspace, or, especially, an attic. Calculating the impact of conductive heat transfer on supply ventilation ducts in unconditioned space is beyond the scope of this report, but we offer a brief qualitative discussion of the relative efficiency of multi-port supply and forced-air supply ventilation ducts.

\section{Figure 4. Multi-Port Supply Ventilation}

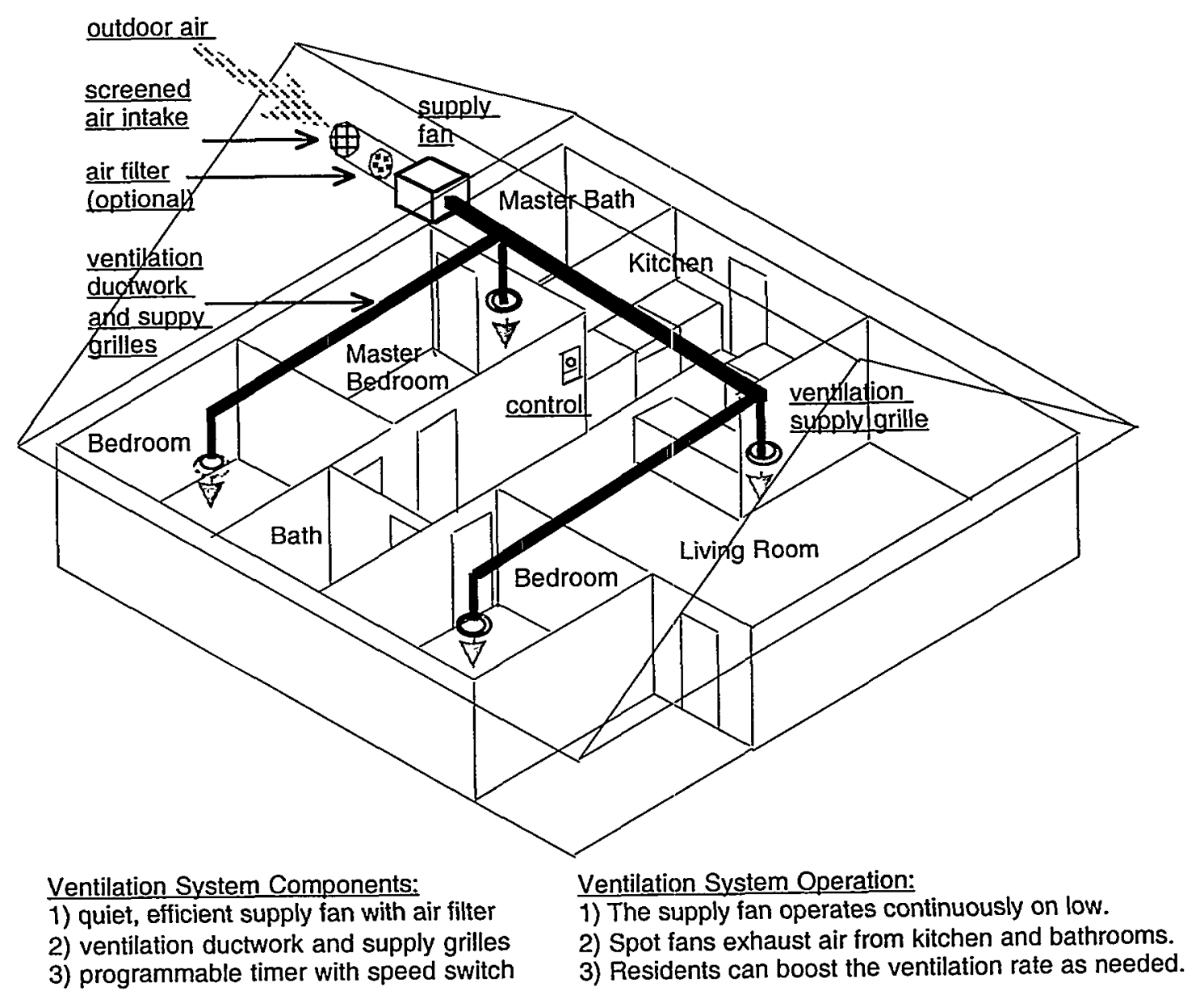

The impact on ventilation operating costs of putting supply ventilation ducts in unconditioned space depends on (1) the difference in temperature of air inside and outside the ducts, (2) ventilation operating schedule (i.e., continuous vs continual), (3) surface area of the ductwork located in unconditioned space, and (4) duct R-value. If we assume multi-port supply and forced-air supply ducts are insulated to the same $\mathrm{R}$-value, three variables remain.

Thermal impact on ducts in unconditioned space is of most concern in homes in hot climates, where supply ducts are usually located in attics, which can reach temperatures of over $150^{\circ} \mathrm{F}$. For example, in a production home in Phoenix with supply ventilation, supply air moves through the attic ventilation ducts continuously. If the home has multi-port supply ventilation, during the summer, outdoor air in the supply ducts is hot (e.g., $95^{\circ} \mathrm{F}$ ) but the attic is hotter (e.g, $120^{\circ} \mathrm{F}$ ), so the supply ducts absorb heat from the attic, increasing the home cooling load. During the winter, the attic is not as hot as during the summer, but is (usually) warmer than outdoors, so the supply ducts still absorb heat from the attic, decreasing the home heating load. 
If the same home has forced-air supply ventilation, air in the supply ducts during the summer is cooler than outdoor air and much cooler than attic air, because a small amount of hot outdoor air is mixed with a large amount of cooled indoor air. When the forced-air fan operates for ventilation only, air moving through the ducts is near indoor temperature $\left(\sim 75^{\circ} \mathrm{F}\right)$, but when the air conditioner is on, air in the ducts is much cooler $\left(\sim 60^{\circ} \mathrm{F}\right)$; in both cases, the supply ducts absorb heat from the attic, increasing the home cooling load. During winter, the attic is usually warmer than outdoor air. When the forced-air system operates for ventilation only, air moving through the supply ducts is near indoor temperature, and whether the ducts gain or lose heat to the attic depends on the degree of attic solar heat gain, i.e., whether the attic is cooler or warmer than the house. But when the forced-air system is heating, air in the ducts (e.g., $100^{\circ} \mathrm{F}$ ) is much warmer than the attic, so the ducts lose heat to the attic, increasing the home heating load.

To the extent that temperature differentials associated with forced-air supply ventilation ducts are greater than multi-port supply ventilation ducts, the impact of conductive heat transfer is greater on forced-air ducts than ventilation-only ducts; this impact can be mitigated if the forced-air supply system operates at regular intervals (rather than continuously) for ventilation.

Ventilation-only ducts are smaller (4-6" diameter) than forced-air ducts (6-18" diameter), so their surface area is much lower. On the other hand, smaller ducts have a greater surface area to volume ratio than forced-air supply ducts (e.g., a 6" diam. ventilation-only duct has a surface area to volume ratio of 0.66 and a 12" diam. forced-air duct has a surface area to volume ratio of 0.33), and this increases the relative impact of conductive heat transfer on the smaller ducts How the interaction of all these variables affects the relative impact of conductive heat transfer on multi-port and forced-air supply ducts in unconditioned space requires further investigation.

\subsection{Balanced Ventilation}

Balanced ventilation uses a supply fan and an exhaust fan to regularly exchange indoor air; both fans move similar volumes of air, so indoor pressure fluctuates near neutral or "balanced." From a safety and health perspective, balanced pressure is better than negative indoor pressure, but not as beneficial as positive indoor pressure, which helps keep outdoor pollutants outdoors (EDU 1996b). The primary advantage of balanced ventilation is the ability to transfer heat between the outgoing (exhaust) and incoming (supply) air streams. When balanced ventilation incorporates heat recovery, comfort is improved because supply air is tempered before delivery, and costs of conditioning ventilation air is significantly reduced, particularly in severe climates (Smith 1994). Balanced ventilation also provides the best distribution of ventilation air, because two fans are used and, when heat recovery is incorporated, both air streams are usually ducted. Another advantage of balanced ventilation systems is that they can be deliberately "unbalanced" to pressurize or depressurize a home, according to the season (White 1998).

\subsubsection{Balanced Ventilation with Heat Recovery}

A balanced heat-recovery ventilation (HRV) system includes an exhaust fan, supply fan, and heat exchanger; ducts connect the exhaust fan to several exhaust ports, usually including one in each bathroom, and the supply fan to several supply grilles, including one in each bedroom. Balanced HRVs are among the more expensive ventilation systems to install, but they are the most affordable to operate. Figure 5 illustrates a balanced heat-recovery ventilation system.

Although the initial cost of heat-recovery is offset by reduced operating cost, its relatively high installation cost currently limits its use by production homebuilders. Another and perhaps more significant disadvantage of balanced heat-recovery systems, at least in production homes, is that they require considerable time and training to install properly. For this reason, builders who offer HRVs as an upgrade should consult closely with the HRV manufacturer during the design phase and consider hiring an HRV contractor trained and recommended by the manufacturer. 


\section{Figure 5. Balanced Heat-recovery Ventilation}

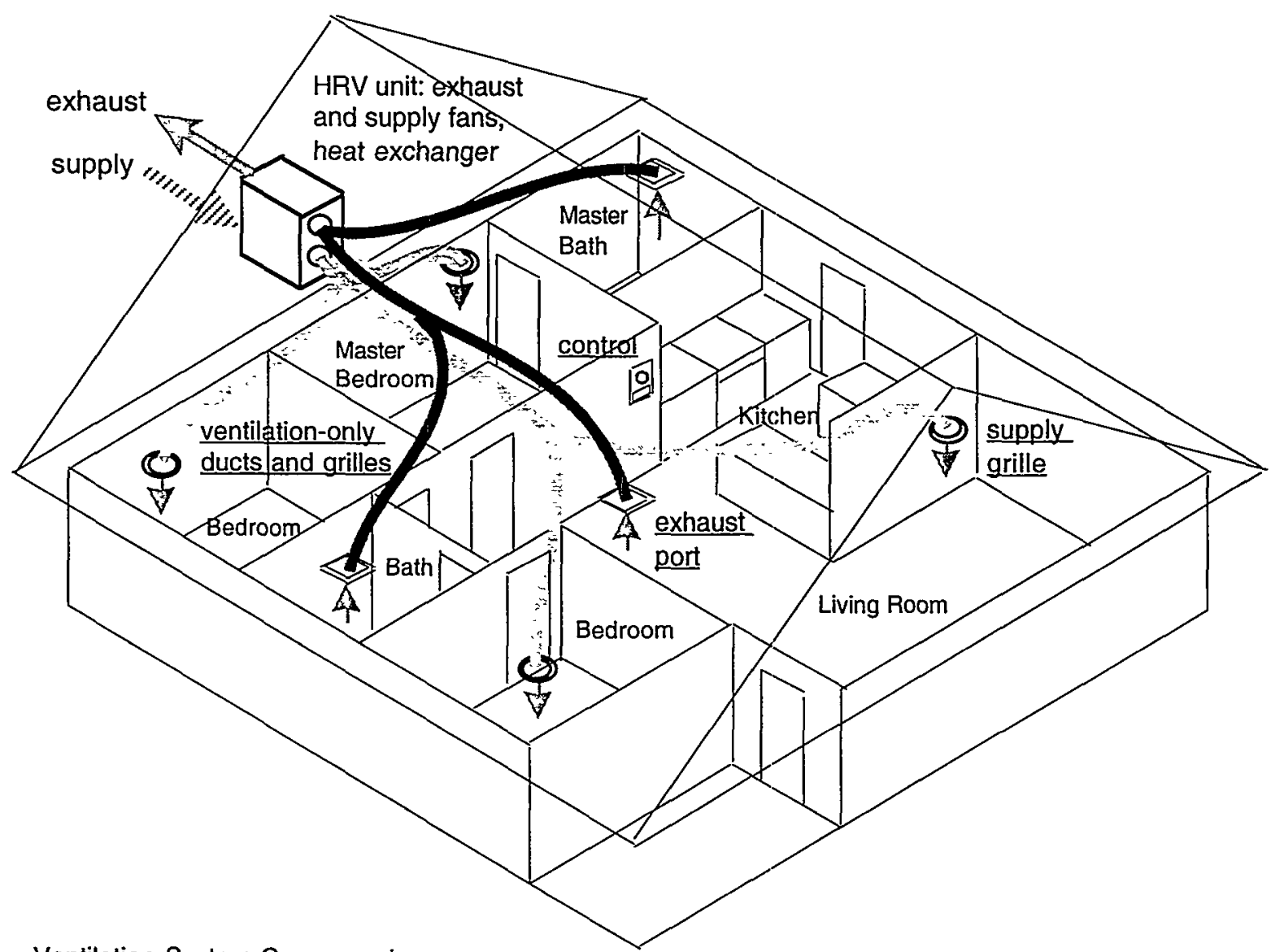

Ventilation System Components:

1) HRV unit containing exhaust and supply fans, and air-to-air heat exchanger

2) exhaust and supply ducts and grilles

3) programmable timer with speed switch
Ventilation System Operation:

1) Air is supplied to bedrooms, exhausted from bathrooms.

2) Sensible heat is recovered from exhausted indoor air.

3) Residents can temporarily boost the ventilation rate.

\subsubsection{Balanced Ventilation without Heat Recovery}

Not all balanced ventilation systems include heat recovery; in some cases, people want balanced pressure without the additional installation cost or advantages of an air-to-air heat exchanger. Therefore, we evaluated two balanced systems without heat recovery: (1) multi-port supply + single-port exhaust, and (2) forced-air supply + single-port exhaust. Each is a combination of forced-air or multi-port supply and single-port exhaust.

\section{Evaluation of Ventilation Systems}

We evaluated ventilation systems in each climate on the basis of three criteria: total annualized cost, distribution of ventilation air within the home, and the system's effect on indoor pressure. To quantitatively compare systems on the basis of our cost and effectiveness criteria, we created a scale and applied relative scores to each ventilation system in each climate. 


\subsection{Ventilation Costs}

\subsubsection{Capital Costs}

Installation cost estimates are based on information provided by manufacturers, distributors, consultants, R.S. Means 1997 Mechanical Cost Data (Means 1997) and a survey of NY and CA contractors ${ }^{12}$ Estimates represent retail costs to the consumer, including materials, labor, and $25 \%$ overhead and profit; they do not include the cost of local (spot) exhaust fans. We assume that ventilation system installation costs are the same in all climates, all systems include a timer with a speed switch, and all exhaust ventilation systems include six passive vents.

Annualized capital cost includes installation cost and periodic equipment replacement costs. We assumed a 20-year ventilation system lifetime, a $7 \%$ real discount rate, and the following:

- Quality PSC ventilation fans (including those in HRVs) that operate continuously require replacement every 10 years at a cost of $\$ 200$ per fan for labor \& material,

- Standard PSC forced-air fans used continuously for ventilation require motor replacements every five years at a (motor) cost of $\$ 200$ for labor \& material, and

- Variable-speed ICM forced-air fans used continuously for ventilation require replacement of controls after 10 years, at a (controls) cost of $\$ 200$, labor \& material.

Ventilation system capital costs are summarized in Table 2 and itemized in Appendix B.

Table 2. Summary of Capital Costs

Systems are sorted by Total Annualized Capital Cost

\begin{tabular}{|c|c|c|c|c|c|c|c|c|}
\hline \multirow{2}{*}{$\begin{array}{l}\text { Ventilation System } \\
\text { Upgraded bath exhaust }\end{array}$} & \multicolumn{2}{|c|}{$\begin{array}{l}\text { Installed (First) Cost } \\
\text { (includes material, } \\
\text { labor, 25\% O\&P) }\end{array}$} & \multicolumn{2}{|c|}{$\begin{array}{l}\text { Present Value of } \\
\text { Equipment Replaced } \\
\text { over } 20 \text { years }\end{array}$} & \multicolumn{2}{|c|}{$\begin{array}{l}\text { Present Value of } \\
\text { All Capital Costs } \\
\text { over } 20 \text { years }\end{array}$} & \multicolumn{2}{|c|}{$\begin{array}{l}\text { Total Annualized } \\
\text { Capital Cost } \\
\text { over } 20 \text { years }\end{array}$} \\
\hline & $\$$ & 463 & $\$$ & 187 & $\$$ & 649 & $\$$ & 60 \\
\hline Single-port exhaust & $\$$ & 613 & $\$$ & 187 & $\$$ & 799 & $\$$ & 74 \\
\hline Forced air supply & $\$$ & 300 & $\$$ & 525 & $\$$ & 825 & $\$$ & 77 \\
\hline Multi-port supply & $\$$ & 650 & $\$$ & 187 & $\$$ & 837 & $\$$ & 78 \\
\hline Multi-port exhaust & $\$$ & 1,125 & $\$$ & 187 & $\$$ & 1,312 & $\$$ & 122 \\
\hline FA supply, SP exhaust & $\$$ & 663 & $\$$ & 700 & $\$$ & 1,362 & $\$$ & 127 \\
\hline MP supply, SP exhaust & $\$$ & 1,013 & $\$$ & 374 & $\$$ & 1,386 & $\$$ & 129 \\
\hline Balanced heat recovery & $\$$ & 1,388 & $\$$ & 374 & $\$$ & 1,761 & $\$$ & 164 \\
\hline ICM forced air supply & $\$$ & 1,550 & $\$$ & 525 & $\$$ & 2,075 & $\$$ & 193 \\
\hline
\end{tabular}

\subsubsection{Operating Costs}

Annual operating costs for each system in each climate were estimated by computer-modeling the interaction of infiltration, mechanical ventilation, and space heating and cooling equipment. The cost of operating a ventilation system includes the energy used by the ventilation fan(s) as well as the cost of tempering ventilation air and any infiltration attributable to active ventilation; it does not include the cost of tempering air that would infiltrate in the absence of ventilation. We estimated operating costs by modeling ventilation system performance. Appendix $C$ shows operating cost estimates, broken down by fan energy, heating, cooling, and total operating cost.

We selected one city to represent each of the four climates: Boston (cold), Washington DC (mixed), Houston (hot humid), and Phoenix (hot arid). Typical Meteorological Year 2 (TMY2)

12 Synertech Systems Corp., Inc. conducted an unpublished survey of residential ventilation costs for NYSERDA (NY State Energy Research and Development Authority), CIEE (CA Institute for Energy Efficiency), and LBNL. 
weather data were used in all modeling. Table 3 lists the home thermal characteristics used in RESVENT and DOE-2 modeling; these are consistent with the ENERGY STAR Homes program, i.e., a Home Energy Rating System (HERS) score of at least 86 points (Birdsall et al. 1990, Marion and Urban 1995). We also assumed that:

- homes have $0.20 \mathrm{AC} / \mathrm{h}$ average annual infiltration (in the absence of mechanical ventilation)

- homes have $0.35 \mathrm{AC} / \mathrm{h}$ mechanical ventilation, and

- homes have three spot exhaust fans (one each in the kitchen and two bathrooms) that operate 30 minutes/day each, and a clothes dryer exhaust fan that operates one hour/week.

We used RESVENT to estimate infiltration- and ventilation-related space conditioning loads, including latent cooling. RESVENT is an hourly ventilation simulation program developed by the Energy Performance of Buildings Group of the Indoor Environment Department at LBNL; it incorporates the Sherman-Grimsrud infiltration model (Matson and Feustel 1998, Sherman and Matson 1996) ${ }^{13}$. We used the ASHRAE 136 method to determine normalized leakage values corresponding to $0.20 \mathrm{AC} / \mathrm{h}$ infiltration (ASJHRAE 1993). Homes were modeled with each ventilation system in addition to $0.20 \mathrm{AC} / \mathrm{h}$ infiltration, and with $0.20 \mathrm{AC} / \mathrm{h}$ infiltration only; loads attributable to $0.20 \mathrm{AC} / \mathrm{h}$ infiltration only are subtracted from loads attributable to $0.35 \mathrm{AC} / \mathrm{h}$ mechanical ventilation plus $0.20 \mathrm{AC} / \mathrm{h}$ infiltration to determine the loads attributable to mechanical ventilation.

Table 3. Energy Star Home Modeling. Assumptions

All homes have $2000 \mathrm{ft}^{2}, 2 \times 4$ frame, $12.5 \%$ window/floor area, and $\mathrm{R}-38$ ceiling insulation.

Cooling equipment is rated 12 SEER; heating equipment is rated $80 \mathrm{AFUE}$ (gas), $3.26 \mathrm{COP}$ (electric).

(Actual heating and cooling equipment efficiencies used in operating cost calculations are listed in Table 5.)

Fractional leakage area is the total leakage area of a building expressed as a fraction of conditioned floor area.

\begin{tabular}{|c|c|c|c|c|}
\hline Home Characteristic & Boston MA & Washington DC & Houston TX & Phoenix AZ \\
\hline Number of stories & 2 & 2 & 1 & 1 \\
\hline $\begin{array}{c}\text { Fractional leakage area } \\
\text { Foundation type } \\
\text { Exterior wall insulation }\end{array}$ & $\begin{array}{c}0.00015 \\
\text { basement } \\
\text { R-19 }\end{array}$ & $\begin{array}{c}0.00022 \\
\text { basement } \\
\text { R-19 }\end{array}$ & $\begin{array}{c}0.00025 \\
\text { slab-on-grade } \\
\text { R-13 }\end{array}$ & $\begin{array}{c}0.00030 \\
\text { slab-on-grade } \\
\text { R-13 }\end{array}$ \\
\hline Exterior wall finish & wood & aluminum & brick & stucco \\
\hline Window Glazing & dbl-pane low-E & dbl-pane low-E & dbl-pane low-E \\
argon gas fill & argon gas fill & $\begin{array}{c}\text { dbl-pane low-E } \\
\text { solar-control }\end{array}$ \\
\hline Window Frame & wood or vinyl & wood or vinyl & $\begin{array}{c}\text { aluminum, no } \\
\text { thermal break }\end{array}$ & $\begin{array}{c}\text { aluminum, no } \\
\text { thermal break }\end{array}$ \\
\hline Window U-factor (Btu/h-ft $\left.{ }^{2}\right)$ & 0.39 & 0.39 & 0.67 & 0.67 \\
\hline Solar heat gain coefficient & 0.52 & 0.52 & 0.37 & 0.37 \\
\hline Duct system efficiency & 0.88 & 0.38 & 0.84 & 0.80 \\
\hline
\end{tabular}

Each home is assumed to have $0.20 \mathrm{AC} / \mathrm{h}$ infiltration (i.e., the amount of air that would infiltrate the home during one year if there were no mechanical ventilation) and each ventilation system continuously delivers $0.35 \mathrm{AC} / \mathrm{h}$. However, mechanical ventilation affects the infiltration rate, so the combined or total air-change rate (ventilation + infiltration) varies for each climate and type of ventilation system (Feustel et al. 1987, Kesselring 1991). Table 4 shows the total air-

13 To the extent that the Sherman-Grimsrud (or LBL) infiltration model consistently and significantly overestimates infiltration rates compared to measured values (Nelson 1998, Palmiter 1991), our operating cost estimates, which are based on this model, should be considered in relative, rather than absolute terms. 
changes for each ventilation system and climate, based on the Sherman-Wilson model, which estimates the interaction of mechanical ventilation and infiltration (Sherman and Wilson 1986).

Table 4. Total Air-Change Rates Mechanical Ventilation + Actual Infiltration (in $\mathrm{AC} / \mathrm{h}$ )

\begin{tabular}{|rccc|}
\hline SYSTEM TYPE: & $\begin{array}{c}\text { EXHAUST } \\
\text { (one fan, passive vents) }\end{array}$ & $\begin{array}{c}\text { SUPPLY } \\
\text { (one fan) }\end{array}$ & $\begin{array}{c}\text { BALANCED } \\
\text { (two fans) }\end{array}$ \\
\hline Boston & 0.47 & 0.44 & 0.61 \\
Washington DC & 0.48 & 0.46 & 0.63 \\
Houston & 0.43 & 0.41 & 0.55 \\
Phoenix & 0.43 & 0.41 & 0.56 \\
\hline
\end{tabular}

The cost of conditioning ventilation air depends on the cost of fuel or electricity used to heat and cool a home as well as the type and efficiency of space heating and cooling equipment. In each climate, we calculated operating costs for homes with two heating and cooling equipment types: gas furnace/central air conditioning (FAC) and, except for Boston, electric heat pumps (EHP). We used 1995 Energy Information Agency (EIA) utility electric and gas prices and assumed that real energy prices are constant throughout the 20 -year ventilation system lifetime. We used measured gas furnace annual fuel utilization efficiency (AFUE) values, and measured air conditioner and heat pump seasonal coefficient-of-performance (COPs) values from EPA's Space Conditioning Report (L'Ecuyer et al. 1993), all of which are shown in Table 5.

\section{Table 5. Fuel Prices and Space Conditioning Equipment Efficiency}

\section{EIA Fuel Prices Actual Space Conditioning Equipment Efficiency}

\begin{tabular}{|c|c|c|c|c|c|c|}
\hline $\begin{array}{c}\text { gas } \\
\$ / \text { therm }\end{array}$ & $\begin{array}{c}\text { electric } \\
\$ / \mathrm{kWh}\end{array}$ & City & $\begin{array}{c}\text { elec heating } \\
\text { COP }\end{array}$ & $\begin{array}{c}\text { elec cooling } \\
\text { COP }\end{array}$ & $\begin{array}{c}\text { gas heating } \\
\text { AFUE }\end{array}$ & measured in \\
\hline 9.27 & 0.125 & Boston & 1.56 & 2.30 & 0.66 & Burlington VT \\
5.84 & 0.081 & Houston & 2.13 & 2.47 & 0.66 & Atlanta GA \\
7.56 & 0.098 & Phoenix & 1.84 & 2.37 & 0.65 & Phoenix AZ \\
6.95 & 0.083 & Wash DC & 1.80 & 2.56 & 0.66 & New York City \\
\hline
\end{tabular}

For forced-air ventilation systems, we needed to know the incremental cost of operating the forced-air fan for ventilation alone. We used the DOE-2 building energy model to determine the hours per year (for each climate and heating/cooling equipment type) that a forced-air fan operates for heating and cooling and (by subtracting from $8,760 \mathrm{hrs} /$ year) for ventilation alone. Thermostat set points used in DOE- 2 modeling are 78 oF for cooling and 68 oF for heating.

To estimate the cost of ventilation fan operation, we assumed a ventilation system static pressure of 0.25 inches water gauge (w.g.) for exhaust and 0.50 inches w.g. for supply (ducted) systems, and energy consumption of $1.00 \mathrm{~W} / \mathrm{cfm}$ for HRVs, $0.60 \mathrm{~W} / \mathrm{cfm}$ for spot exhaust fans, 0.50 W/cfm for PSC forced-air fans, $0.30 \mathrm{~W} / \mathrm{cfm}$ for PSC ventilation fans, and $0.25 \mathrm{~W} / \mathrm{cfm}$ for ICM forced-air fans. ${ }^{14}$ We assumed a sensible heat recovery efficiency of $70 \%$ for balanced HRVs; we did not model freeze protection in HRVs. Table 6 summarizes annual operating costs.

Figures 6-12 show total annualized costs by city and space conditioning equipment type. Appendix C itemizes all ventilation system costs: installation cost, annualized capital cost, operating costs (broken down by fan energy, heating, cooling, and total), and total annual costs.

14 ICM and PSC forced-air fan W/cfm rates are based on measured data from Danny Parker of the Florida Solar Energy Center; HRV and other ventilation fan W/cfm rates are based on product literature from fan manufacturers. 


\section{Table 6. Summary of Ventilation Annual Operating Costs}

Systems sorted by Annual Operating Cost in homes with Gas Furnace/AC

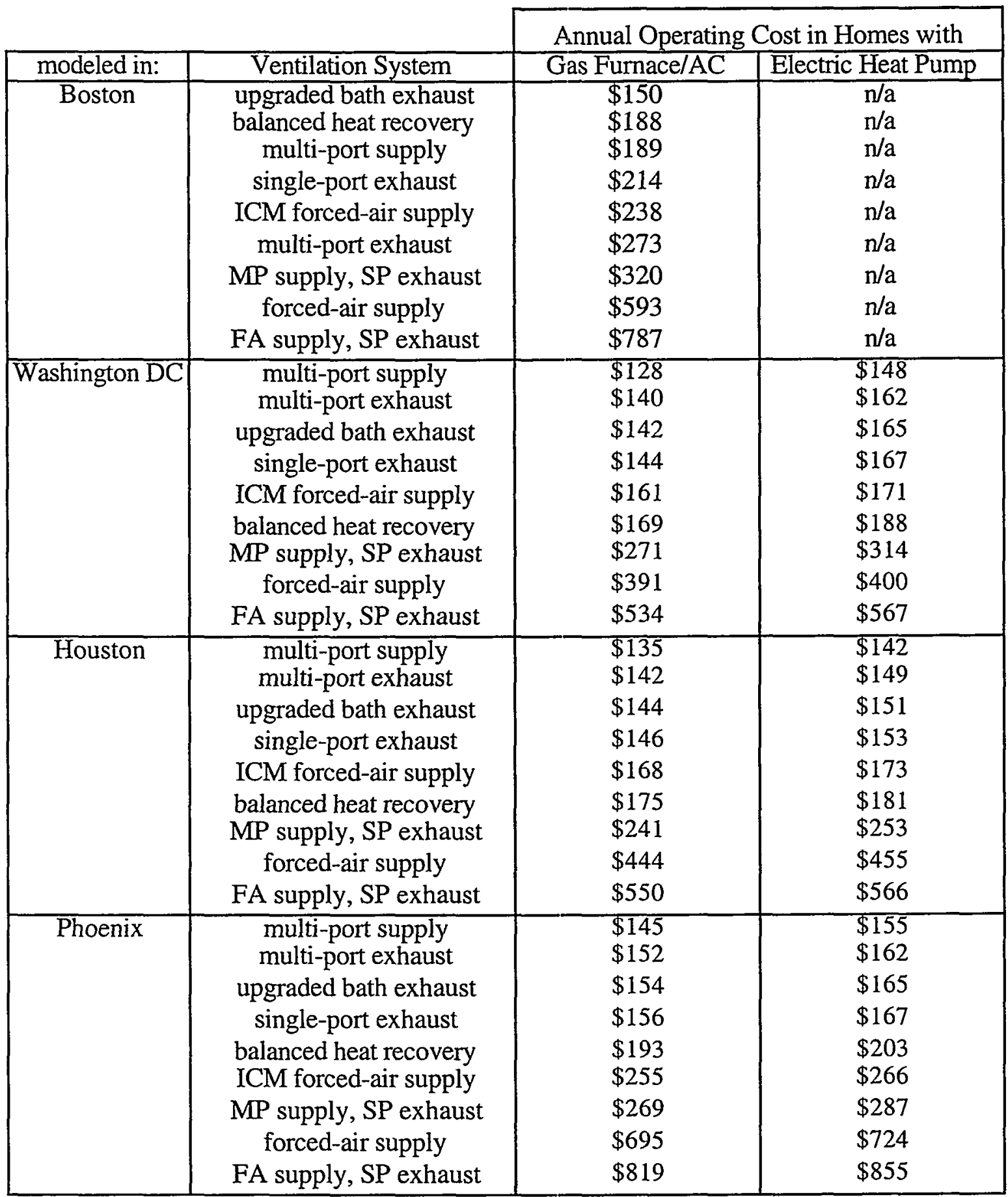

Ventilation operation costs in Table 6 include ventilation fan energy, the cost of tempering ventilation air, and the cost of tempering infiltration attributable to mechanical ventilation. 
Figure 6. Ventilation Costs in Boston Homes with Gas Furnace/AC

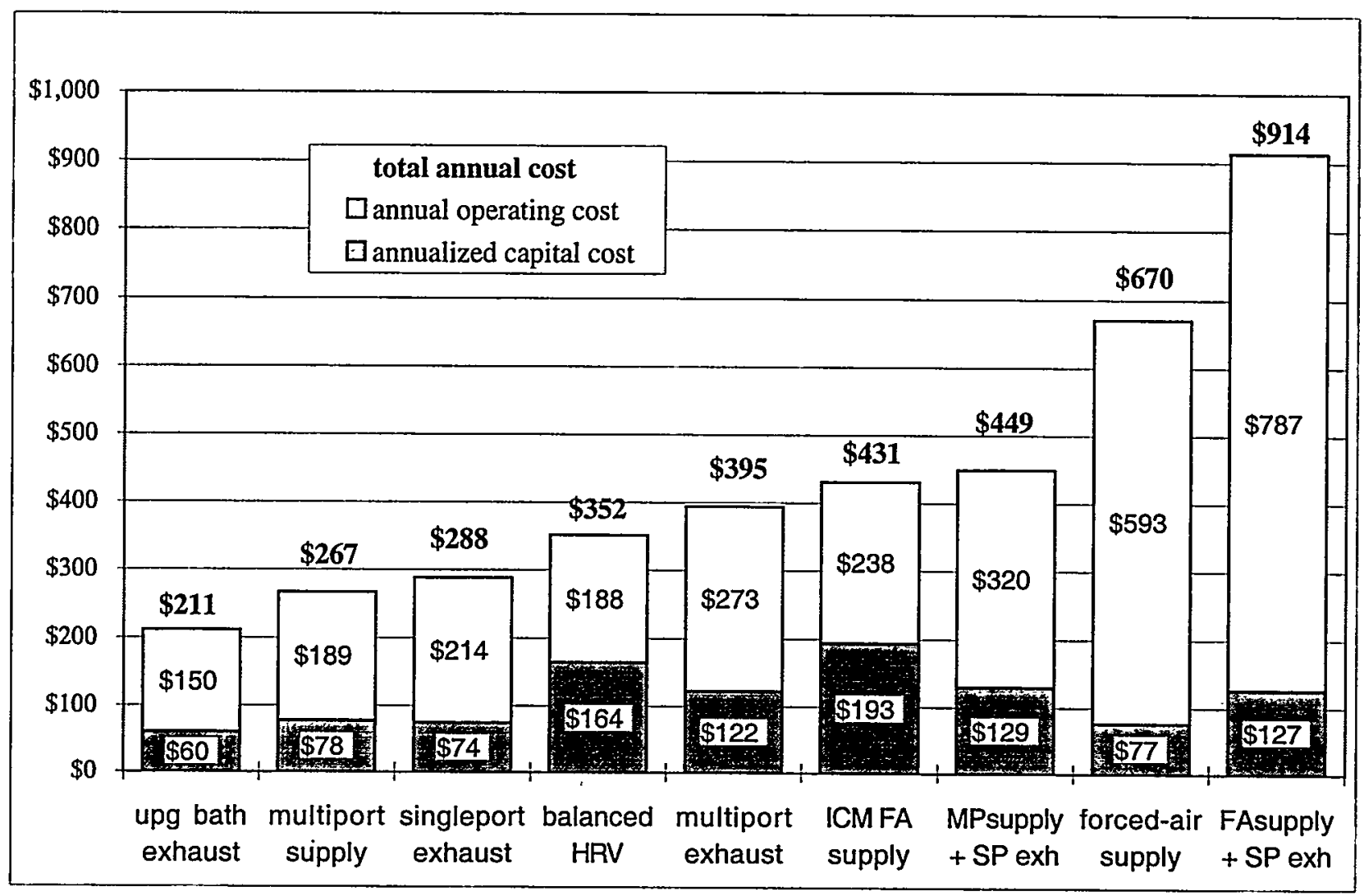

\section{Abbreviations used in Figures 6-12}

exh exhaust

FA forced-air

HRV heat recovery ventilation

ICM integrated-control motor

MP multi-port

SP single-port

upg upgraded 
Figure 7. Ventilation Costs in Washington DC Homes with Gas Furnace/AC

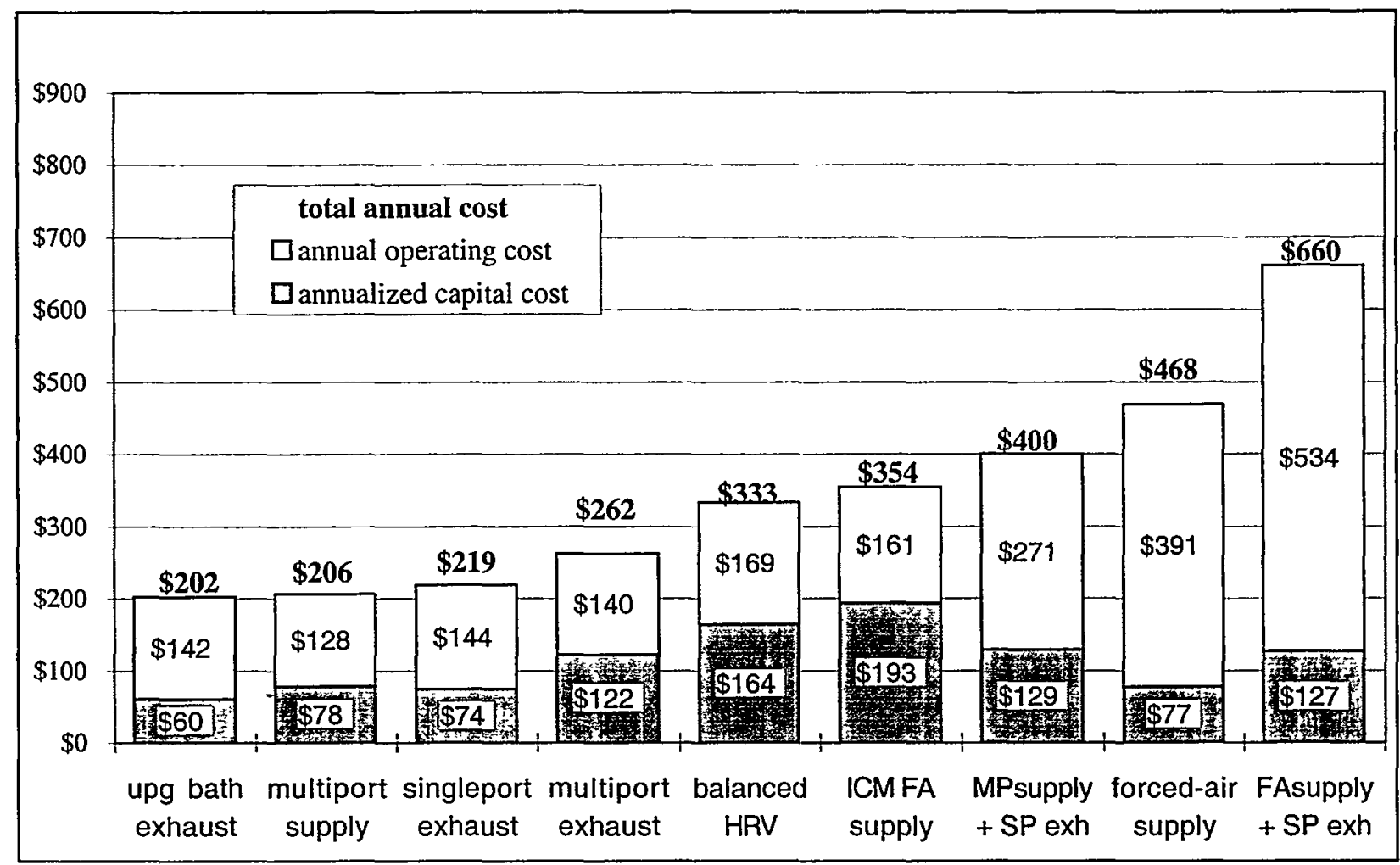

Figure 8. Ventilation Costs in Washington DC Homes with Electric Heat Pumps

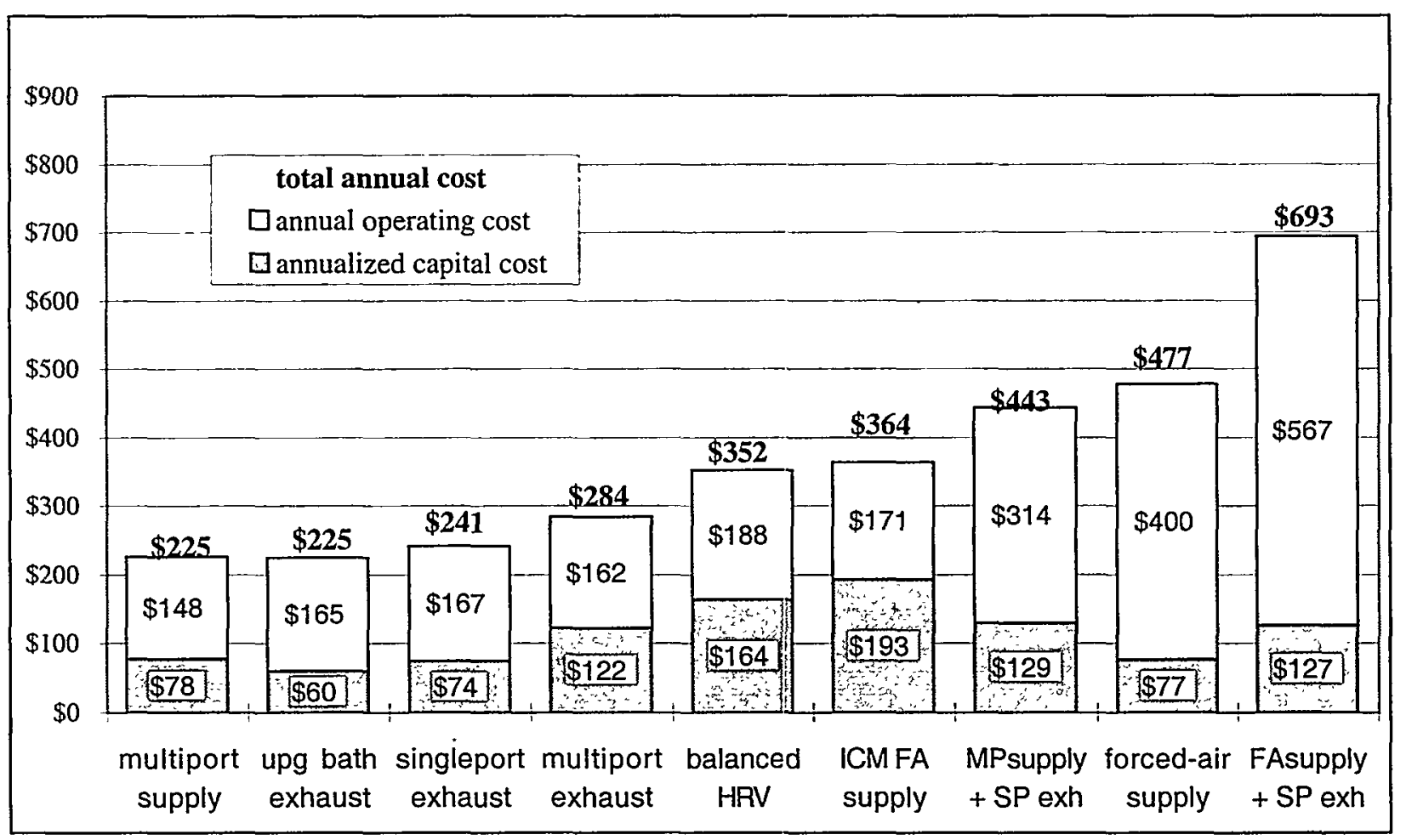


Figure 9. Ventilation Costs in Houston Homes with Gas Furnace/AC

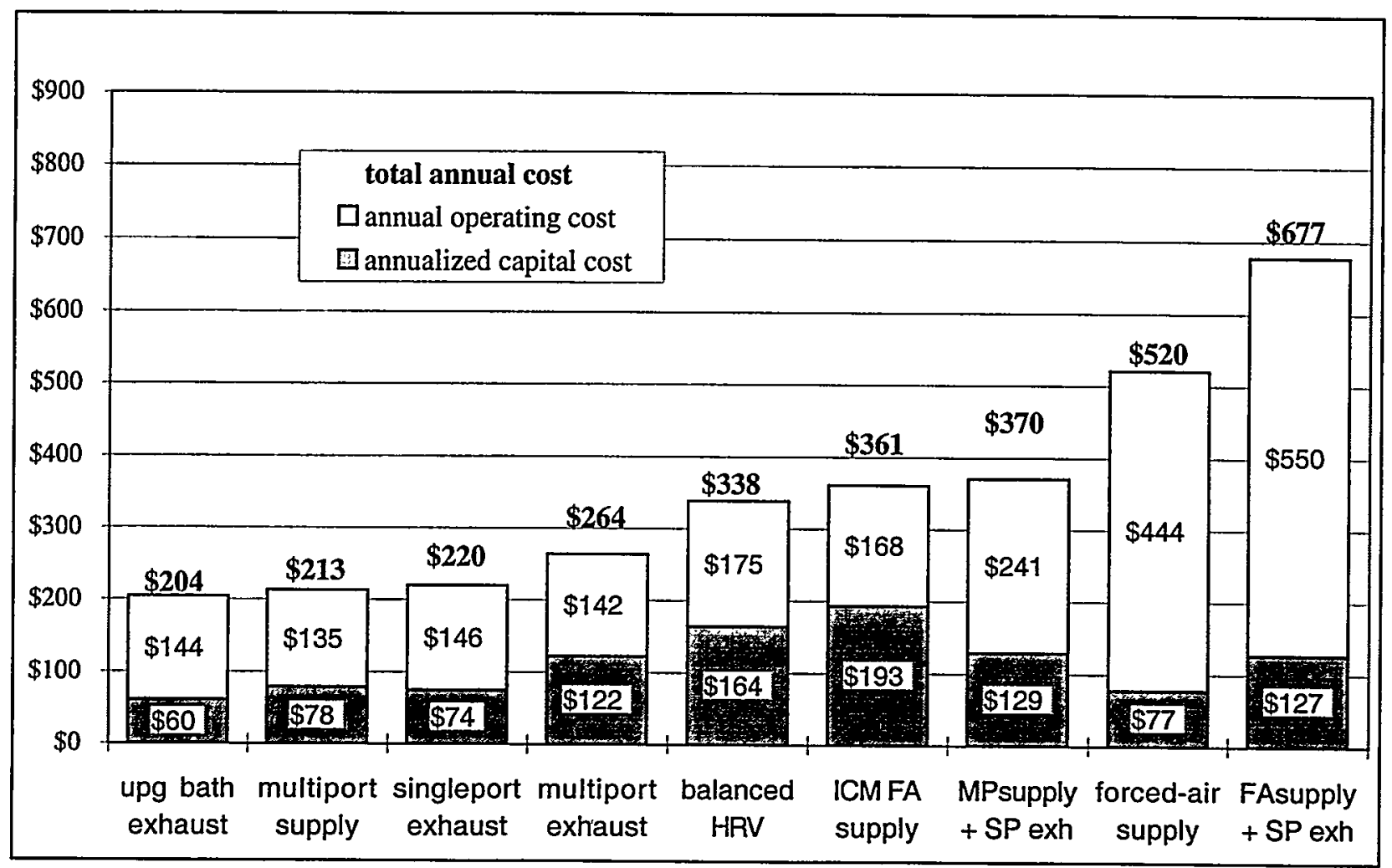

Figure 10. Ventilation Costs in Houston Homes with Electric Heat Pump

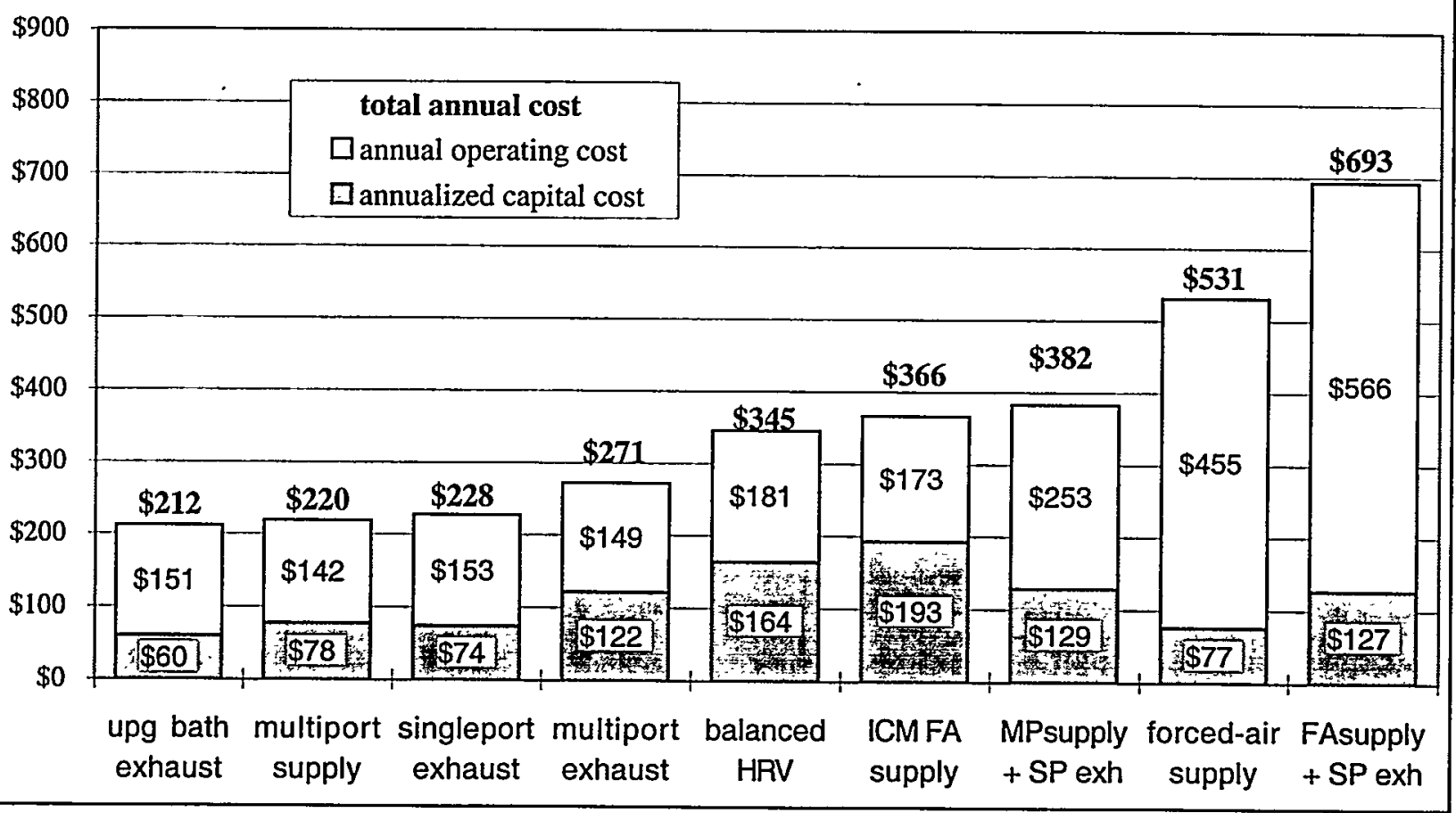


Figure 11. Ventilation costs in Phoenix Homes with Gas Furnace/AC

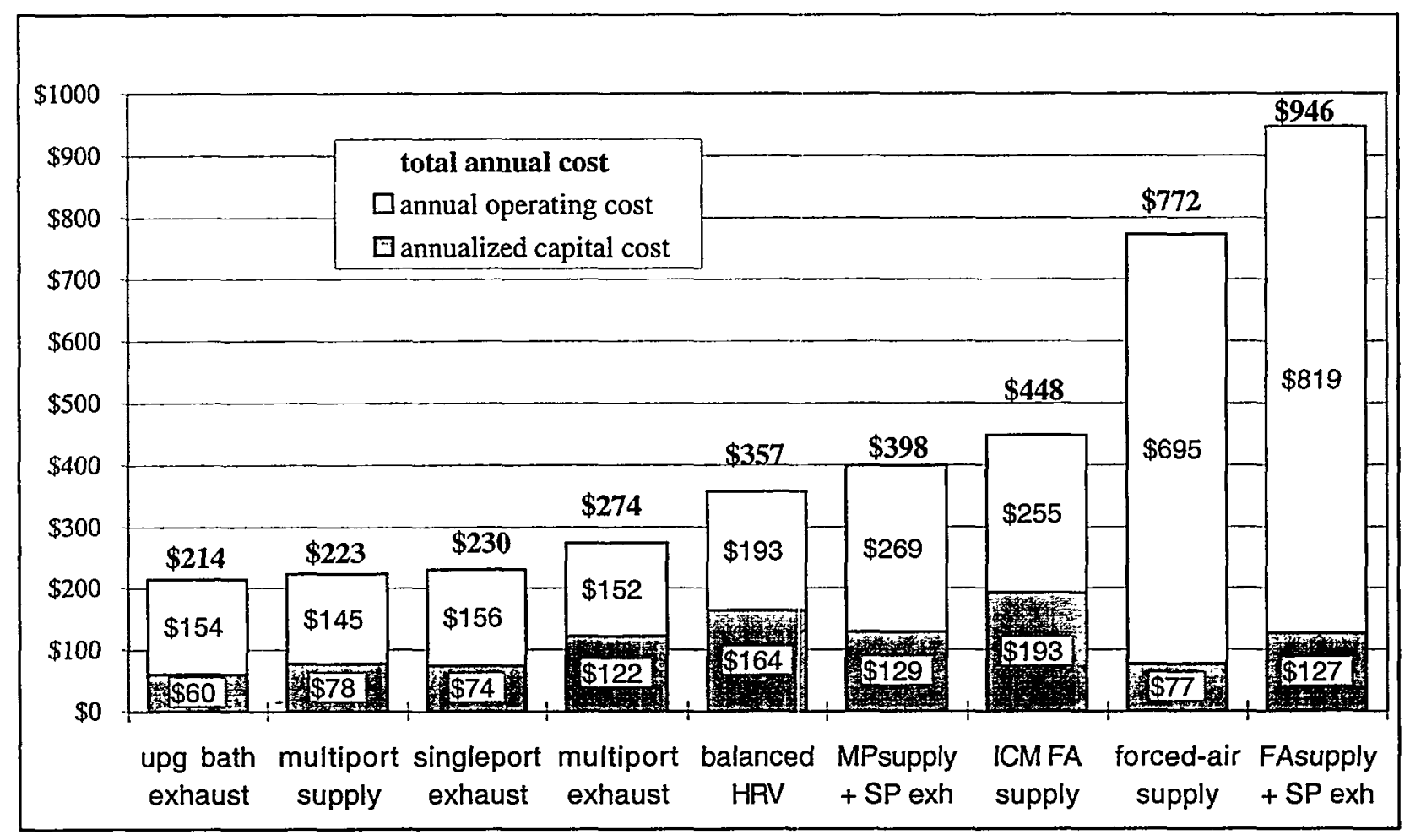

Figure 12. Ventilation Costs in Phoenix Homes with Electric Heat Pump

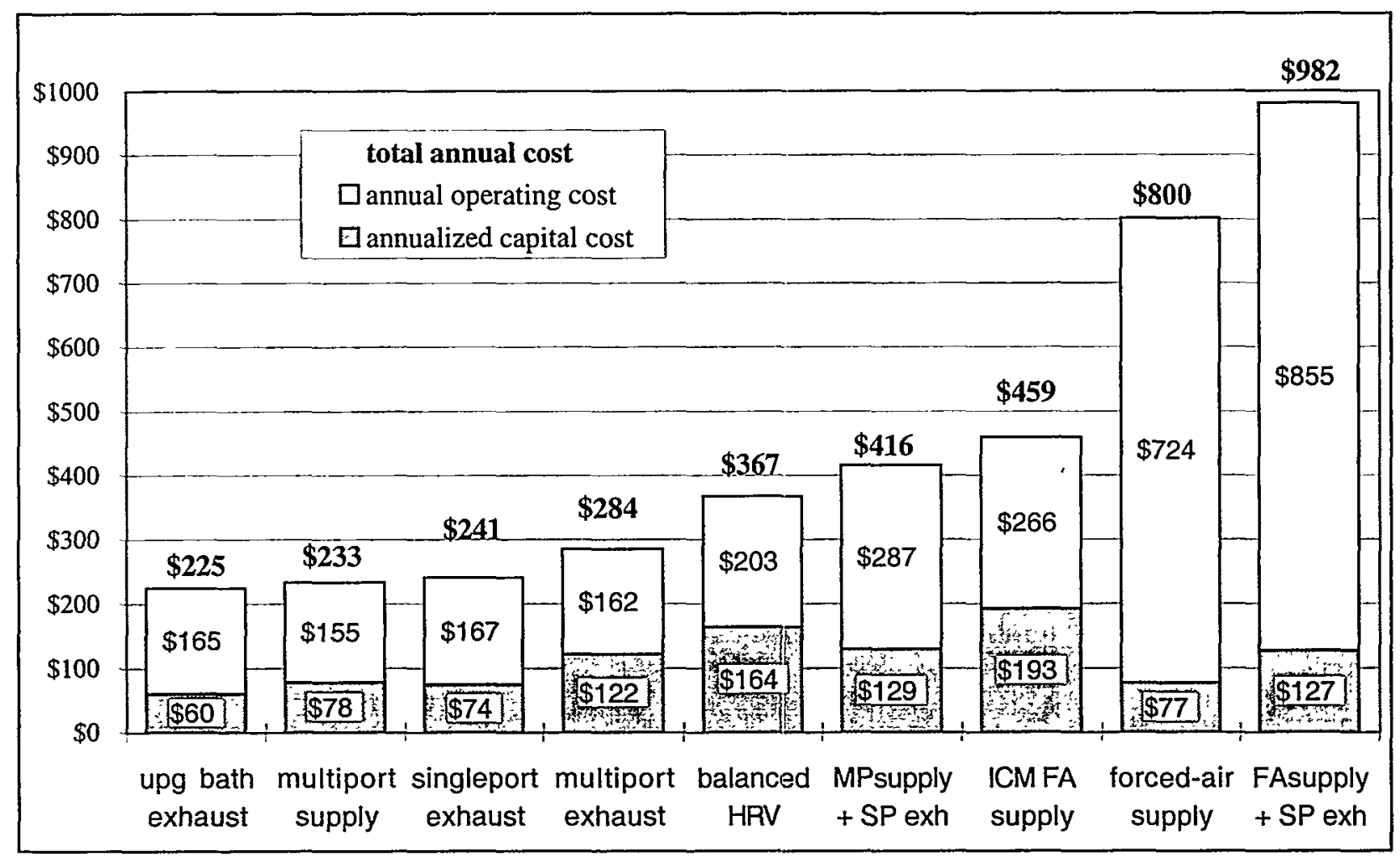




\subsection{Ranking Ventilation Systems by Cost and Effectiveness}

We assigned relative scores to each system in each climate for three criteria: total annual cost, effective distribution of ventilation air, and predominant indoor pressure (resulting from continuous ventilation). Table 7 presents our method of assigning scores. Total annualized costs incorporate capital as well as operating costs, annualized over a 20 -year system lifetime. We assign $50 \%$ of the total score to total annualized costs, $25 \%$ to indoor pressure, and $25 \%$ to distribution. By giving total annualized cost twice the weight of the other two criteria, our analysis, in effect, gives equal weight to costs and effectiveness. Although this (or any) scale is necessarily somewhat arbitrary, it allows us to compare systems according to quantitative and non-quantitative criteria. Of course, any other numeric scale could be used, and different or additional criteria (e.g., the ability to filter air) could be considered and differently weighted.

\section{Table 7. Scoring Method}

Each ventilation system in each climate is given a score for three criteria.

\begin{tabular}{|c|c|c|c|}
\hline Score & Total Annual Cost & Score & Predominant Indoor Pressuire \\
\hline 6 & $\leq \$ 250$ & 6 & positive (supply systems) \\
\hline 5 & $\$ 251-300$ & & \\
\hline 4 & $\$ 301-350$ & & \\
\hline 3 & $\$ 351-400$ & 3 & near neutral (balanced systems) \\
\hline 2 & $\$ 401-450$ & & \\
\hline 1 & $\$ 451-500$ & & \\
\hline 0 & $>\$ 500$ & 0 & negative (exhaust systems) \\
\hline Score & \multicolumn{3}{|c|}{ Distribution of Ventilation Air Within the Home } \\
\hline 6 & \multicolumn{3}{|c|}{ air is supplied (ducted) to and exhausted from several locations } \\
\hline 5 & \multicolumn{3}{|c|}{ air is supplied (ducted) to several rooms and exhausted centrally } \\
\hline 4 & \multicolumn{3}{|c|}{ air is supplied (ducted) to several rooms } \\
\hline 3 & \multicolumn{3}{|c|}{ air is exhausted from several rooms } \\
\hline 2 & \multicolumn{3}{|c|}{ air is exhausted from one central location } \\
\hline 1 & \multicolumn{3}{|c|}{ air is exhausted from one bathroom } \\
\hline
\end{tabular}

Table 8 shows individual and total scores of ventilation systems by climate and equipment type. Total annualized costs are weighted by a factor of two. Total score is the sum of three scores. 
Table 8. Ventilation System Scores

Systems are sorted by Total Score

\begin{tabular}{|c|c|c|c|c|c|c|c|c|}
\hline \multirow{3}{*}{ BOSTON } & \multicolumn{4}{|c|}{ Total Annual Cost } & \multirow{3}{*}{\begin{tabular}{|l|} 
Effective \\
Distribution
\end{tabular}} & \multirow{3}{*}{\begin{tabular}{|l} 
Indoor \\
Pressure
\end{tabular}} & \multirow{2}{*}{\multicolumn{2}{|c|}{$\begin{array}{c}\text { Total Score } \\
\text { (sum of } 3 \text { scores) }\end{array}$}} \\
\hline & \multicolumn{2}{|c|}{ Score } & \multicolumn{2}{|c|}{ Score $\times 2$} & & & & \\
\hline & $\overline{\mathrm{FAC}}$ & $\overline{\mathrm{EHP}}$ & $\overline{\mathrm{FAC}}$ & $\overline{\mathrm{EHP}}$ & & & FAC & $\overline{\mathrm{EHP}}$ \\
\hline multi-port supply & 5 & $\mathrm{n} / \mathrm{a}$ & 10 & $\mathrm{n} / \mathrm{a}$ & $\overline{4}$ & 6 & 20 & $\mathrm{n} / \mathrm{a}$ \\
\hline balanced heat recovery & 3 & $\mathrm{n} / \mathrm{a}$ & 6 & $\mathrm{n} / \mathrm{a}$ & 6 & 3 & 15 & $\mathrm{n} / \mathrm{a}$ \\
\hline ICM forced air supply & 2 & $\mathrm{n} / \mathrm{a}$ & 4 & $\mathrm{n} / \mathrm{a}$ & 4 & 6 & 14 & $\mathrm{n} / \mathrm{a}$ \\
\hline upgraded bath exhaust & 6 & $\mathrm{n} / \mathrm{a}$ & 12 & $\mathrm{n} / \mathrm{a}$ & 1 & 0 & 13 & $\mathrm{n} / \mathrm{a}$ \\
\hline MP supply, SP exhaust & 2 & $\mathrm{n} / \mathrm{a}$ & 4 & $\mathrm{n} / \mathrm{a}$ & 5 & 3 & 12 & $\mathrm{n} / \mathrm{a}$ \\
\hline single-port exhaust & 5 & $\mathrm{n} / \mathrm{a}$ & 10 & $\mathrm{n} / \mathrm{a}$ & 2 & 0 & 12 & $\mathrm{n} / \mathrm{a}$ \\
\hline forced air supply & 0 & $\mathrm{n} / \mathrm{a}$ & 0 & $\mathrm{n} / \mathrm{a}$ & 4 & 6 & 10 & $\mathrm{n} / \mathrm{a}$ \\
\hline multi-port exhaust & 3 & $\mathrm{n} / \mathrm{a}$ & 6 & $\mathrm{n} / \mathrm{a}$ & 3 & 0 & 9 & $\mathrm{n} / \mathrm{a}$ \\
\hline FA supply, SP exhaust & 0 & $\mathrm{n} / \mathrm{a}$ & 0 & $\mathrm{n} / \mathrm{a}$ & 5 & 3 & 8 & $\mathrm{n} / \mathrm{a}$ \\
\hline WASHINGTON DC & & & 0 & & & & $\overline{\text { FAC }}$ & $\overline{\mathrm{EHP}}$ \\
\hline multi-port supply & 6 & 6 & 12 & 12 & 4 & 6 & 22 & 22 \\
\hline balanced heat recovery & 4 & 3 & 8 & 6 & 6 & 3 & 17 & 15 \\
\hline ICM forced air supply & 3 & 3 & 6 & 6 & 4 & 6 & 16 & 16 \\
\hline single-port exhaust & 6 & 6 & 12 & 12 & 2 & 0 & 14 & 14 \\
\hline MP supply, SP exhaust & 3 & 2 & 6 & 4 & 5 & 3 & 14 & 12 \\
\hline multi-port exhaust & 5 & 5 & 10 & 10 & 3 & 0 & 13 & 13 \\
\hline upgraded bath exhaust & 6 & 6 & 12 & 12 & 1 & 0 & 13 & 13 \\
\hline forced air supply & 1 & 1 & 2 & 2 & 4 & 6 & 12 & 12 \\
\hline FA supply, SP exhaust & 0 & 0 & 0 & 0 & 5 & 3 & 8 & 8 \\
\hline HOUSTON & & & & & & & $\overline{F A C}$ & $\overline{\mathrm{EHP}}$ \\
\hline multi-port supply & 6 & 6 & 12 & 12 & 4 & 6 & 22 & 22 \\
\hline balanced heat recovery & 4 & 4 & 8 & 8 & 6 & 3 & 17 & 17 \\
\hline ICM forced air supply & 3 & 3 & 6 & 6 & 4 & 6 & 16 & 16 \\
\hline MP supply, SP exhaust & 3 & 3 & 6 & 6 & 5 & 3 & 14 & 14 \\
\hline single-port exhaust & 6 & 6 & 12 & 12 & 2 & 0 & 14 & 14 \\
\hline multi-port exhaust & 5 & 5 & 10 & 10 & 3 & 0 & 13 & 13 \\
\hline upgraded bath exhaust & 6 & 6 & 12 & 12 & 1 & 0 & 13 & 13 \\
\hline forced air supply & 0 & 0 & 0 & 0 & 4 & 6 & 10 & 10 \\
\hline FA supply, SP exhaust & 0 & 0 & 0 & 0 & 5 & 3 & 8 & 8 \\
\hline PHOENIX & & & & & & & $\overline{\mathrm{FAC}}$ & $\overline{\mathrm{EHP}}$ \\
\hline multi-port supply & 6 & 6 & $\overline{12}$ & 12 & 4 & 6 & 22 & 22 \\
\hline balanced heat recovery & 3 & 3 & 6 & 6 & 6 & 3 & 15 & 15 \\
\hline ICM forced air supply & 2 & 1 & 4 & 2 & 4 & 6 & 14 & 12 \\
\hline MP supply, SP exhaust & 3 & 2 & 6 & 4 & 5 & 3 & 14 & 12 \\
\hline single-port exhaust & 6 & 6 & 12 & 12 & 2 & 0 & 14 & 14 \\
\hline multi-port exhaust & 5 & 5 & 10 & 10 & 3 & 0 & 13 & 13 \\
\hline upgraded bath exhaust & 6 & 6 & 12 & 12 & 1 & 0 & 13 & 13 \\
\hline forced air supply & 0 & 0 & 0 & 0 & 4 & 6 & 10 & 10 \\
\hline FA supply, SP exhaust & 0 & 0 & 0 & 0 & 5 & 3 & 8 & 8 \\
\hline
\end{tabular}




\section{Dehumidification}

Indoor relative humidity (RH) should be kept between $40 \%$ and $60 \%$; higher $\mathrm{RH}$ can lead to condensation on surfaces and favor the growth of microorganisms; lower RH causes static electricity and dry nasal passages; the latter increases susceptibility of occupants to infection. Sources of moisture in homes can be categorized as internal (those generated by the building and its occupants) and external (outdoor air introduced by infiltration, ventilation, or both). In mechanically ventilated homes in hot humid climates, and in any climate with hot humid weather (e.g., dew point exceeds $60-70^{\circ} \mathrm{F}$ for several months), removal of moisture from ventilation air is important for occupant comfort and to control growth of mold, mildew, and dust mites (Barringer 1989, Bower 1995, Gehring 1998). We examined the options available for controlling ventilation latent loads. These options, which are discussed in detail in Appendix E, include air-conditioning, dehumidifying supply ventilation units, and balanced energy-recovery ventilation that transfers latent and sensible heat between air streams.

Most new U.S. homes have air-conditioning and increasing numbers have ventilation systems. Home heating and cooling equipment should be sized and selected to meet the calculated sensible and latent loads for each house, and in homes with mechanical ventilation, calculations should include the external load of ventilation air. In addition to proper sizing and selection, cooling equipment must also be properly installed in order to achieve manufacturer-rated efficiency and latent capacity. Therefore, the first steps that homebuilders should take towards controlling ventilation latent loads is to size cooling equipment according to Manual $D$, select equipment using Manual $S$, and install equipment according to manufacturer instructions and industry performance standards (ACCA 1992, ACCA 1995b, Davis 1998b).

When air-conditioning is absent or inadequate to control moisture from mechanical ventilation, other options are available for removing moisture from outdoor air before it enters the home. A dehumidifying supply ventilation unit (DSVU) is an efficient whole-house dehumidifier that filters and dehumidifies ventilation air before distributing it through supply ventilation ducts. DSVUs add to supply ventilation installation and operating costs, but control indoor RH within a relatively precise range. Balanced energy-recovery ventilation units (ERVs) with rotary desiccant cores passively transfer moisture between the more humid and less humid air streams. An ERV would be installed instead of supply ventilation, and does not increase operating costs; however, neither the direction nor the amount of ERV moisture transfer can be controlled. See Appendix $E$ for a more thorough discussion of these moisture control strategies.

\section{Discussion}

Our comparative evaluation of residential ventilation systems begins with estimated capital costs. Appendix B. Itemized Capital Costs provides the details of our installation cost estimates and sorts systems by installation cost. According to our estimates, forced-air supply is the least expensive and ICM forced-air supply is the most expensive system to install. In Table 2. Summary of Capital Costs ventilation systems are sorted by total annualized capital cost, which includes equipment replacement as well as installation costs. Upgraded bath exhaust is the least and ICM forced-air supply is the most expensive system with regard to annualized capital costs.

Next we estimate and compare annual operating costs, which vary by location (i.e., climate and fuel prices) and the type of space heating and cooling equipment installed in the home. Operating costs are summarized in Table 6 , which sorts ventilation systems by annual operating costs. Appendix $C$ breaks operating costs into fan energy and tempering (heating and cooling) costs. Based on operating costs alone, upgraded bath exhaust and multi-port supply are among the least expensive systems for all climates and both equipment types; balanced heat-recovery, multi-port exhaust and single-port exhaust systems are also among the less expensive systems, depending on climate. Forced-air supply and the two balanced systems without heat recovery are most expensive to operate in all climates for both equipment types, but the reduced cost of operating ICM forced-air supply (c.f., forced-air supply) make this system more competitive. 
Total annualized costs, which include annualized capital cost and annual operating cost, are shown in Appendix C and Figures 6-12. Upgraded bath exhaust, multi-port supply, and single-port exhaust are consistently the least expensive, while forced-air supply and forced-air supply + single-port exhaust are consistently most expensive in terms of total annualized cost.

Finally, we compare ventilation systems on the basis of two effectiveness criteria as well as cost. With regard to effective distribution of ventilation air, balanced systems are preferable to supply systems, which are preferable to exhaust systems; the explanation for this is given in Table 7 . With regard to predominant indoor pressure resulting from continuous ventilation, supply systems are preferable to balanced systems, and balanced systems are preferable to exhaust systems, which can sustain depressurization. We apply a weighting factor of two to our total annualized cost scores so that ventilation system cost and effectiveness receive equal weight in our evaluation. The results of our cost and effectiveness evaluation are shown in Table 8.

Total scores presented in Table 8 compare ventilation systems on the basis of our quantitative (costs) and non-quantitative (effectiveness) evaluation criteria. They are not, however, the only basis for our recommendations. We also take into account our minimum criteria, particularly the fact that we want to avoid positive indoor pressure (supply ventilation) in cold climates, and the fact that, at present, production builder decisions are driven more by installation costs than by ventilation system lifetime cost or effectiveness. In the production homebuilding industry, builders decide what (if any) ventilation system will be installed, and a ventilation system has to be selected and installed before it can improve indoor air quality, comfort, and operating costs.

\subsection{Limitations of the Analysis}

As with any analysis, assumptions have a significant effect on the results. Actual installation costs vary by region and may be affected by recent technological developments. Our estimated operating costs are specific to the weather and fuel prices for those cities that we selected to represent each climate, and to our assumptions about house characteristics (e.g., living area, leakage area, equipment efficiency), occupant behavior (e.g., spot fans are used 30 min per day), and ventilation systems (e.g., fan power consumption, heat recovery efficiency). Operating costs for other locations, house characteristics, and ventilation system specifications will vary. Different weighting factors could be used to score the systems. In addition, continuous $0.35 \mathrm{AC} / \mathrm{h}$ mechanical ventilation does not necessarily ensure quality indoor air; the amount of ventilation a home needs depends on many factors, including occupant perceptions.

\section{Recommendations}

As the results in Table 8 show, multi-port supply ventilation has the highest score in all climates for both types of heating and cooling equipment. We therefore recommend multi-port supply ventilation in mixed, hot arid, and hot humid climates, and emphasize that ventilation sensible and latent loads should be accounted for during the sizing and selection of cooling equipment. If the cooling equipment cannot accommodate the latent load of ventilation air, we recommend that production builders offer dehumidifying supply ventilation units to buyers as an upgrade.

In cold climates, we want to avoid positive indoor pressure (which can cause condensation in exterior walls) during the heating season; therefore we recommend that multi-port supply be balanced by single-port exhaust ventilation. In the heating season, residents should operate both fans for balanced ventilation, but between heating seasons, they have the option of operating balanced ventilation or multi-port supply ventilation. The benefits of using only the supply fan during warmer weather include positive indoor pressure and lower operating costs. Balanced heat-recovery scores second or third in all climates, reduces operating costs, distributes air well, and, especially in cold climates, improves comfort by tempering supply air. The installation cost of balanced heat recovery is relatively high but, as with other products, unit price drops as volume increases, and production builders may realize volume discounts. Therefore, we recommend that builders in cold climates offer HRVs to buyers as an upgrade. 
For builders who still install forced-air supply ventilation because of its low installation cost, we recommend optimizing forced-air system performance, indoor air quality, and homeowner satisfaction by (1) ensuring ducts are airtight or in conditioned space, (2) installing a control that automatically operates the forced-air fan 20 minutes during each hour that the fan does not operate for heating or cooling, ${ }^{15}$ and (3) offering ICM forced-air fans to buyers as an upgrade.

Regardless of which ventilation system is installed, controls should be clearly and permanently labeled with basic operating instructions, e.g., "This switch controls the house ventilation system. It should be ON whenever the home is occupied." Every ventilation system should be commissioned at installation to verify that ventilation ducts are airtight and that the proper (design) airflow is actually delivered to and/or exhausted from each space under operating conditions. Operation and maintenance details should be provided in a Homeowner's Manual.

Table 9. Summary of Ventilation Recommendations

\begin{tabular}{|c|c|}
\hline $\begin{array}{l}\text { Mixed, Hot Arid and } \\
\text { Hot Humid Climates }\end{array}$ & Caveats \\
\hline Multi-port supply & $\begin{array}{l}\text { Include ventilation loads in sizing and selection of } \\
\text { cooling equipment (ACCA Manuals } J \text { and } S \text { ). }\end{array}$ \\
\hline Forced-air supply & $\begin{array}{l}\text { Include ventilation loads in sizing and selection of } \\
\text { cooling equipment (ACCA Manuals J and S). } \\
\text { Forced-air ducts must be airtight or within } \\
\text { conditioned space. } \\
\text { Automatically control the forced-air fan to } \\
\text { operate at regular intervals for ventilation. } \\
\text { Offer ICM forced-air fans to buyers as an upgrade. }\end{array}$ \\
\hline Cold Climate & Caveats \\
\hline Multi-port supply + Single-port exhaust & $\begin{array}{l}\text { Include ventilation loads in sizing and selection of } \\
\text { cooling equipment (ACCA Manuals J and S). } \\
\text { Use balanced ventilation during heating season, } \\
\text { and balanced or supply ventilation otherwise. } \\
\text { Offer balanced HRVs to buyers as an upgrade. }\end{array}$ \\
\hline Forced-air supply + Single-port exhaust & $\begin{array}{l}\text { Include ventilation loads in sizing and selection of } \\
\text { cooling equipment (ACCA Manuals J and S). } \\
\text { Forced-air ducts must be airtight or within } \\
\text { conditioned space. } \\
\text { Install a control that operates the forced-air fan } \\
\text { at regular intervals for ventilation. } \\
\text { Automatically control the forced-air fan to } \\
\text { operate at regular intervals for ventilation. } \\
\text { Use balanced ventilation during heating season } \\
\text { and balanced or supply ventilation otherwise. } \\
\text { Offer ICM forced-air fans to buyers as an upgrade. } \\
\text { Offer balanced HRVs to buyers as an upgrade. }\end{array}$ \\
\hline
\end{tabular}

15 These forced-air fan controls cost \$50-100, not including installation, and are available from DuroDyne Corp. (800) 899-3876 and Armin Rudd of the Florida Solar Energy Center (407) 638-1402. 


\section{Appendix A. When Is Continuous Depressurization of Homes Safe?}

Before installing exhaust ventilation in tight homes, it is important to verify that the following circumstances have been met, i.e., that depressurization is not a safety and health risk to occupants.

EITHER There are no combustion appliances in these homes,

OR 1) All combustion appliances have separate, sealed supply and exhaust venting, and

2) All are free of manufacturing defects or damage from transport, and

3) All are properly installed and regularly maintained by qualified personnel, and

4) Occupants never install any natural-draft gas appliance or other combustion source.

AND,

EITHER There are no fireplaces in these homes,

OR 1) Fireplaces have separate and adequate air supply and combustion venting, and

2) Fireplace doors are tested and sufficiently air tight, and

3) Fireplace doors are always closed during operation.

AND,

EITHER There are no attached garages in these homes,

OR 1) Occupants never operate a car in the garage with the garage door closed, and

2) There is no air leakage (infiltration) in walls between the house and garage, and

3) The door between the home and garage is never open when an auto is idling.

AND,

EITHER The homes are not located in high-radon areas,

OR A radon-mitigation system is properly installed and continuously working,

OR 1) There are no holes in the foundation, and

2) There never will be any cracks in the foundation.

It may be possible to satisfy all these conditions for a particular home for a foreseeable period during which its furnishings and occupants and their behavior are known, but it is very difficult to confidently assume that these conditions are met throughout the life of any particular home and impossible to assume these conditions for all the homes in a subdivision or a new-home program. 


\section{Appendix B. Itemized Capital Costs}

Systems are sorted by Installation Cost

\begin{tabular}{|c|c|c|c|c|c|c|c|c|c|}
\hline SYSTEM COMPONENTS & $\begin{array}{l}\text { Forced-Air } \\
\text { (FA) } \\
\text { Supply }\end{array}$ & $\begin{array}{l}\text { Upgraded } \\
\text { Bath } \\
\text { Exhaust }\end{array}$ & $\begin{array}{l}\text { Single-port } \\
\text { (SP) } \\
\text { Exhaust }\end{array}$ & $\begin{array}{l}\text { Multi-Port } \\
\text { (MP) } \\
\text { Supply }\end{array}$ & $\begin{array}{l}\text { Forced-Air } \\
\text { Supply with } \\
\text { SP Exhaust }\end{array}$ & $\begin{array}{l}\text { Multi-Port } \\
\text { Supply with } \\
\text { SP Exhaust }\end{array}$ & $\begin{array}{c}\text { Multi-Port } \\
\text { (MP) } \\
\text { Exhaust }\end{array}$ & $\begin{array}{c}\text { Balanced } \\
\text { Heat } \\
\text { Recovery }\end{array}$ & $\begin{array}{l}\text { ICM } \\
\text { Forced-Air } \\
\text { Supply }\end{array}$ \\
\hline ventilation fan (or kit), wholesale & & $\$ 120$ & $\$ 120$ & $\$ 150$ & $\$ 120$ & $\$ 270$ & $\$ 400^{\circ}$ & $\$ 700$ & \\
\hline outside-air duct with motorized damper & $\$ 120$ & & & & $\$ 120$ & & & & $\$ 120$ \\
\hline 20 ' sheet metal duct ( $\$ 1 /$ linear $\mathrm{ft})$ & $\$ 20$ & & & & $\$ 20$ & & & & $\$ 20$ \\
\hline passive wall vents $(6 \times \$ 25$ each $)$ & & $\$ 150$ & $\$ 150$ & & & & $\$ 150$ & & \\
\hline $4^{\prime \prime}$ diam alum flex duct ( $\$ 1 /$ linear $\mathrm{ft}$ ) & & & $\$ 20$ & $\$ 100$ & $\$ 20$ & $\$ 120$ & $\$ 100$ & $\$ 125$ & \\
\hline 4" diameter ceiling grilles ( $\$ 5$ each) & & & & $\$ 20$ & & $\$ 20$ & included & $\$ 35$ & \\
\hline incremental cost of ICM fan & & & & & . & & & & $\$ 1,000$ \\
\hline programmable control and wiring & $\$ 50$ & $\$ 50$ & $\$ 50$ & $\$ 50$ & $\$ 50$ & $\$ 50$ & $\$ 50$ & $\$ 50$ & $\$ 50$ \\
\hline subtract bath fans replaced ( $\$ 50$ ea $)$ & & $(\$ 50)$ & & & & & $(\$ 100)$ & $(\$ 100)$ & \\
\hline MATERIALS & $\$ 190$ & $\$ 270$ & $\$ 340$ & $\$ 320$ & $\$ 330$ & $\$ 460$ & $\$ 600$ & $\$ 810$ & $\$ 1,190$ \\
\hline installation time (hours) & 2 & 4 & 6 & 8 & 8 & 14 & 12 & 12 & 2 \\
\hline LABOR @ \$25/hr & $\$ 50$ & $\$ 100$ & $\$ 150$ & $\$ 200$ & $\$ 200$ & $\$ 350$ & $\$ 300$ & $\$ 300$ & $\$ 50$ \\
\hline materials and labor & $\$ 240$ & $\$ 370$ & $\$ 490$ & $\$ 520$ & $\$ 530$ & $\$ 810$ & $\$ 900$ & $\$ 1,110$ & $\$ 1,240$ \\
\hline $25 \%$ overhead and profit & $\$ 60$ & $\$ 93$ & $\$ 123$ & $\$ 130$ & $\$ 133$ & $\$ 203$ & $\$ 225$ & $\$ 278$ & $\$ 310$ \\
\hline INSTALLATION COST & $\$ 300$ & $\$ 463$ & This & $\$ 650$ & and $\$ 663$ & * $\$ \$ 1,013$ & $\$ 1,125$ & $\$ 1,388$ & $4,51,550$ \\
\hline equipment replacement @ 5 yrs & $\$ 200$ & & & & $\$ 200$ & & & & \\
\hline equipment replacement @ 10 yrs & $\$ 200$ & $\$ 200$ & $\$ 200$ & $\$ 200$ & $\$ 400$ & $\$ 400$ & $\$ 200$ & $\$ 400$ & $\$ 200$ \\
\hline equipment replacement @ 15 yrs & $\$ 200$ & & & & $\$ 200$ & & & & \\
\hline present value of replacement costs & $\$ 525$ & $\$ 187$ & $\$ 187$ & $\$ 187$ & $\$ 700$ & $\$ 374$ & $\$ 187$ & $\$ 374$ & $\$ 525$ \\
\hline total present value capital cost & $\$ 825$ & $\$ 649$ & $\$ 799$ & $\$ 837$ & $\$ 1,362$ & $\$ 1,386$ & $\$ 1,312$ & $\$ 1,761$ & $\$ 2,075$ \\
\hline ANNUALIZED CAPITAL COST & $\$ 77$ & $\$ 60$ & $\$ 74$ & $\$ 78$ & $\$ 127$ & $\$ 129$ & $\$ 122$ & $\$ 164$ & $\$ 193$ \\
\hline
\end{tabular}

We assume a $7 \%$ discount rate and 20 -year ventilation system lifetime for annualization of equipment costs.

Itemized components and costs are provided as examples only and should not be construed as system specifications.

Actual costs will vary depending on locale, specific equipment, order volume, and familiarity of installers with each system.

Annualized capital cost $=$ present value of capital costs $x\left(r \times(1+r)^{\wedge} n\right) \div\left((1+r)^{\wedge} n-1\right)$; where $r=$ discount rate, $n=20$ years 


\section{Appendix C. Itemized Capital and Operating Costs Systems are sorted by Total Annualized Cost}

Ventilation operation costs include ventilation fan energy, the cost of tempering ventilation air, and the cost of tempering infiltration attributable to mechanical ventilation.

\begin{tabular}{|c|c|c|c|c|c|c|c|c|c|c|c|}
\hline \multicolumn{3}{|c|}{ Boston homes with Gas Furnace/AC } & \multirow{2}{*}{\multicolumn{2}{|c|}{$\begin{array}{l}\text { annualized } \\
\text { capital cost }\end{array}$}} & \multicolumn{6}{|c|}{ annual operating cost } & \multirow{2}{*}{$\begin{array}{c}\text { Annual } \\
\text { Cost }\end{array}$} \\
\hline Ventilation System & ins & on cost & & & & nergy & heating & & ling & total & \\
\hline upgraded bath exhaust & $\$$ & 463 & $\$$ & 60 & $\$$ & 64 & $\$ 130$ & & & $\$ 150$ & $\$ 211$ \\
\hline ply & $\$$ & 650 & $\$$ & 78 & $\$$ & 65 & $\$ 109$ & & 15 & $\$ 189$ & $\$ 267$ \\
\hline aust & $\$$ & 613 & $\$$ & 74 & $\$$ & 65 & $\$ 132$ & $\$$ & 18 & $\$ 214$ & 288 \\
\hline balance & $\$$ & 1,388 & $\$$ & 164 & $\$$ & 126 & $\$ 109$ & $\$$ & 15 & $\$ 188$ & $\$ 352$ \\
\hline exhaust & $\$$ & 1,125 & $\$$ & 122 & $\$$ & 64 & $\$ 128$ & & 17 & $\$ 273$ & 95 \\
\hline air supply & $\$$ & 1,550 & $\$$ & 193 & $\$$ & 158 & 71 & & 9 & $\$ 238$ & $\$ 431$ \\
\hline P exhaust & $\$$ & 1,013 & $\$$ & 129 & $\$$ & 127 & $\$ 227$ & & 28 & $\$ 320$ & $\$ 449$ \\
\hline & $\$$ & 300 & $\$$ & 77 & $\$$ & 469 & $\$ 109$ & & 15 & $\$ 593$ & $\$ 670$ \\
\hline exhaust & $\$$ & 663 & $\$$ & 127 & $\$$ & 532 & $\$ 227$ & $\$$ & 28 & $\$ 787$ & $\$ 914$ \\
\hline
\end{tabular}

\begin{tabular}{|c|c|c|c|c|c|c|c|c|c|c|}
\hline \multirow{2}{*}{\multicolumn{3}{|c|}{$\frac{\text { Wash DC homes with Gas Furnace/AC }}{\text { Ventilation System installation cost }}$}} & \multirow{2}{*}{\multicolumn{2}{|c|}{$\begin{array}{l}\text { annualized } \\
\text { capital cost }\end{array}$}} & \multicolumn{5}{|c|}{ annual operating cost } & \multirow{2}{*}{$\begin{array}{l}\text { Total } \\
\text { Annual } \\
\text { Cost }\end{array}$} \\
\hline & & & & & & tergy & heating & cooling & total & \\
\hline upgraded bath exhaust & $\$$ & 463 & $\$$ & 60 & $\$$ & 43 & & $\$ 20$ & $\$ 142$ & $\$ 202$ \\
\hline multi-port supply & $\$$ & 650 & $\$$ & 78 & $\$$ & 43 & 68 & 18 & $\$ 128$ & $\$ 206$ \\
\hline single-port exhaust & $\$$ & 613 & $\$$ & 74 & $\$$ & 43 & 81 & 20 & $\$ 144$ & $\$ 219$ \\
\hline multi-port exhaust & $\$$ & 1,125 & $\$$ & 122 & $\$$ & 42 & 78 & 20 & $\$ 140$ & $\$ 262$ \\
\hline balanced heat recovery & $\$$ & 1,388 & $\$$ & 164 & $\$$ & 84 & 68 & 18 & $\$ 169$ & $\$ 333$ \\
\hline ICM forced-air supply & $\$$ & 1,550 & $\$$ & 193 & $\$$ & 103 & 47 & 11 & $\$ 161$ & $\$ 354$ \\
\hline MP supply, SP exhaust & $\$$ & 1,013 & $\$$ & 129 & $\$$ & 85 & $\$ 153$ & 34 & $\$ 271$ & $\$ 400$ \\
\hline forced-air supply & $\$$ & 300 & $\$$ & 77 & $\$$ & 306 & $\$ 68$ & 18 & $\$ 391$ & $\$ 468$ \\
\hline FA supply, SP exhaust & $\$$ & 663 & $\$$ & 127 & $\$$ & 348 & $\$ 153$ & 34 & $\$ 534$ & $\$ 660$ \\
\hline
\end{tabular}

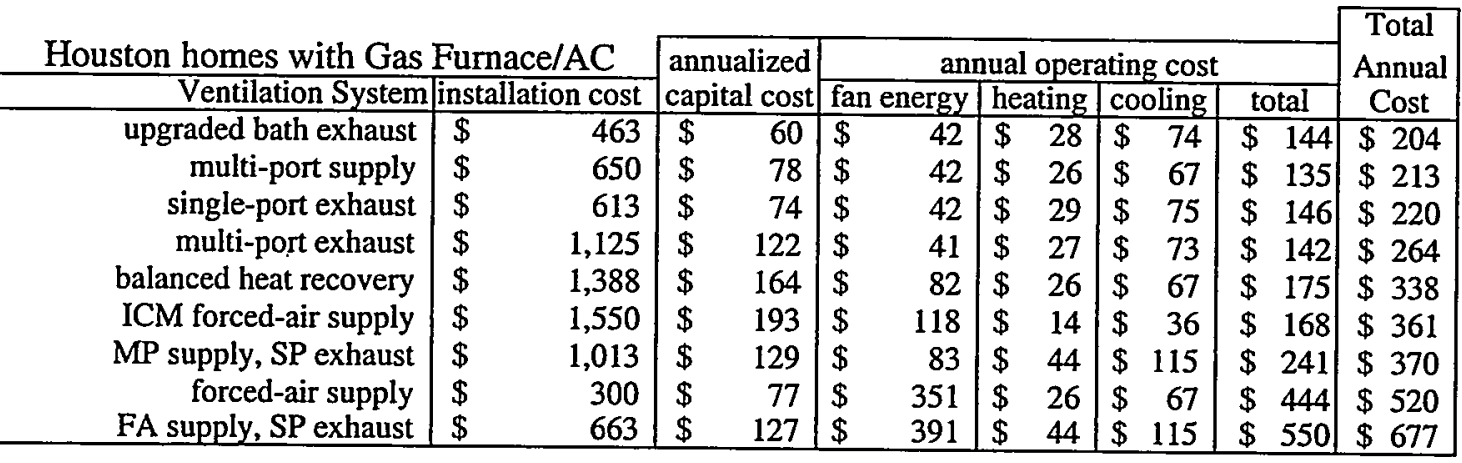

\begin{tabular}{|c|c|c|c|c|c|c|c|c|c|c|c|c|}
\hline \multirow{2}{*}{\multicolumn{3}{|c|}{$\frac{\text { Phoenix homes with Gas Furnace/AC }}{\text { Ventilation System/installation cost }}$}} & \multirow{2}{*}{\multicolumn{2}{|c|}{ capital cost }} & \multicolumn{7}{|c|}{ annual operating cost } & \multirow{2}{*}{$\begin{array}{c}\text { Total } \\
\text { Annual } \\
\text { Cost }\end{array}$} \\
\hline & & & & & & nergy & hea & ting & & oling & total & \\
\hline upgraded bath exhaust & $\$$ & 463 & $\$$ & 60 & $\$$ & 50 & & 32 & & 71 & $\$ 154$ & $\$ 214$ \\
\hline multi-port supply & $\$$ & 650 & $\$$ & 78 & $\$$ & 51 & $\$$ & 30 & $\$$ & 64 & $\$ 145$ & $\$ 223$ \\
\hline ort exhaust & $\$$ & 613 & $\$$ & 74 & $\$$ & 51 & $\$$ & 33 & $\$$ & 72 & $\$ 156$ & $\$ 230$ \\
\hline multi-port exhaust & $\$$ & 1,125 & $\$$ & 122 & $\$$ & 50 & $\$$ & 31 & $\$$ & 70 & $\$ 152$ & $\$ 274$ \\
\hline balanced heat recovery & $\$$ & 1,388 & $\$$ & 164 & $\$$ & 99 & $\$$ & 30 & & 64 & $\$ 193$ & $\$ 357$ \\
\hline MP supply, SP exhaust & $\$$ & 1,013 & $\$$ & 129 & $\$$ & 100 & $\$$ & 51 & & 119 & $\$ 269$ & $\$ 398$ \\
\hline ICM forced-air supply & $\$$ & 1,550 & $\$$ & 193 & $\$$ & 202 & $\$$ & 15 & $\$$ & 37 & $\$ 255$ & $\$ 448$ \\
\hline -air supply & $\$$ & 300 & $\$$ & 77 & $\$$ & 601 & $\$$ & 30 & & 64 & $\$ 695$ & $\$ 772$ \\
\hline FA supp & $\$$ & 663 & $\$$ & 127 & $\$$ & 650 & $\$$ & 51 & $\$$ & 119 & $\$ 819$ & $\$ 946$ \\
\hline
\end{tabular}




\section{Appendix C. Itemized Capital and Operating Costs \\ Systems are sorted by Total Annualized Cost}

Ventilation operation costs include ventilation fan energy, the cost of tempering ventilation air, and the cost of tempering infiltration attributable to mechanical ventilation.

\begin{tabular}{|c|c|c|c|c|c|c|c|c|c|c|c|}
\hline \multirow{3}{*}{\multicolumn{3}{|c|}{$\frac{\text { Wash DC homes with Electric Heat Pump }}{\text { Ventilation System|installation cost }}$}} & \multirow{3}{*}{\multicolumn{2}{|c|}{$\begin{array}{l}\text { annualized } \\
\text { capital cost }\end{array}$}} & & & & & & & \multirow{3}{*}{$\begin{array}{c}\text { Total } \\
\text { Annual } \\
\text { Cost }\end{array}$} \\
\hline & & & & & \multicolumn{6}{|c|}{ annual operating cost } & \\
\hline & & & & & \multicolumn{2}{|c|}{ fan energy } & heating & \multicolumn{2}{|c|}{ cooling } & total & \\
\hline multi-port supply & $\$$ & 650 & $\$$ & 78 & $\$$ & 43 & & & & $\$ 148$ & $\$ 225$ \\
\hline upgraded bath exhaust & $\$$ & 463 & $\$$ & 60 & $\$$ & 43 & $\$ 102$ & $\$$ & 20 & $\$ 165$ & $\$ 225$ \\
\hline single-port exhaust & $\$$ & 613 & $\$$ & 74 & $\$$ & 43 & $\$ 104$ & $\$$ & 20 & $\$ 167$ & $\$ 241$ \\
\hline multi-port exhaust & $\$$ & 1,125 & $\$$ & 122 & $\$$ & 42 & $\$ 100$ & $\$$ & 20 & $\$ 162$ & $\$ 284$ \\
\hline balanced heat recovery & $\$$ & 1,388 & $\$$ & 164 & $\$$ & 84 & 87 & $\$$ & 18 & $\$ 188$ & $\$ 352$ \\
\hline ICM forced-air supply & $\$$ & 1,550 & $\$$ & 193 & $\$$ & 100 & 61 & $\$$ & 11 & $\$ 171$ & $\$ 364$ \\
\hline MP supply, SP exhaust & $\$$ & 1,013 & $\$$ & 129 & $\$$ & 85 & $\$ 196$ & $\$$ & 34 & $\$ 314$ & $\$ 443$ \\
\hline forced-air supply & $\$$ & 300 & $\$$ & 77 & $\$$ & 296 & 87 & $\$$ & 18 & $\$ 400$ & $\$ 477$ \\
\hline FA supply, SP exhaust & $\$$ & 663 & $\$$ & 127 & $\$$ & 337 & $\$ 196$ & $\$$ & 34 & $\$ 567$ & $\$ 693$ \\
\hline
\end{tabular}

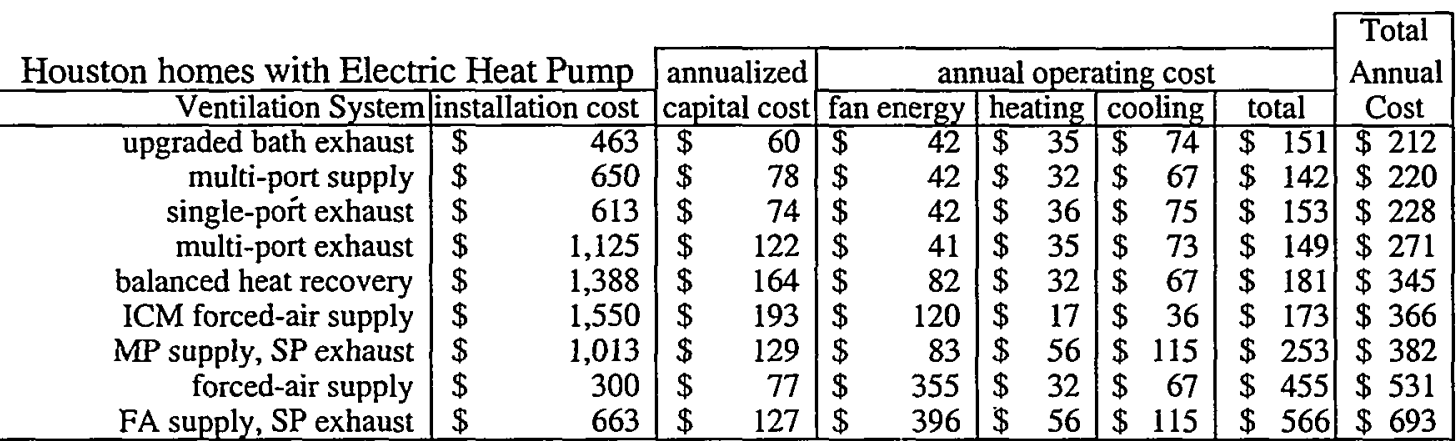

\begin{tabular}{|c|c|c|c|c|c|c|c|c|c|c|c|}
\hline \multirow{2}{*}{\multicolumn{3}{|c|}{ Phoenix homes with Electric Heat Pump }} & \multirow{3}{*}{\multicolumn{2}{|c|}{$\begin{array}{l}\text { annualized } \\
\text { capital cost }\end{array}$}} & & & & & & & \multirow{3}{*}{$\begin{array}{c}\text { Total } \\
\text { Annual } \\
\text { Cost }\end{array}$} \\
\hline & & & & & \multicolumn{6}{|c|}{ annual operating cost } & \\
\hline Ventilation System & ins & on cost & & & $\overline{\text { fan }}$ & nergy & hea & ting & cooling & total & \\
\hline upgraded bath exhaust & $\$$ & 463 & $\$$ & 60 & $\$$ & 50 & $\$$ & 43 & $\$ 71$ & $\$ 165$ & $\$ 225$ \\
\hline oply & $\$$ & 650 & $\$$ & 78 & $\$$ & 51 & $\Psi$ & 40 & 64 & $\$ 155$ & $\$ 233$ \\
\hline $\sin$ & $\$$ & 613 & $\$$ & 74 & $\$$ & 51 & $\$$ & 44 & 72 & $\$ 167$ & $\$ 241$ \\
\hline & $\$$ & 1,125 & $\$$ & 122 & $\$$ & 50 & $\$$ & 42 & 70 & $\$ 162$ & $\$ 284$ \\
\hline balance & $\$$ & 1,388 & $\$$ & 164 & $\$$ & 99 & $\$$ & 40 & 64 & $\$ 203$ & $\$ 367$ \\
\hline MP s & $\$$ & 1,013 & $\$$ & 129 & $\$$ & 100 & $\$$ & 68 & $\$ 119$ & $\$ 287$ & $\$ 416$ \\
\hline r supply & $\$$ & 1,550 & $\$$ & 193 & $\$$ & 208 & $\$$ & 21 & 37 & $\$ 266$ & $\$ 459$ \\
\hline & $\$$ & 300 & $\$$ & 77 & $\$$ & 619 & $\$$ & 40 & 64 & $\$ 724$ & $\$ 800$ \\
\hline FA supply, SP exh & $\$$ & 663 & $\$$ & 127 & $\$$ & 668 & $\$$ & 68 & $\$ 119$ & $\$ 855$ & $\$ 982$ \\
\hline
\end{tabular}




\section{Appendix D. Infiltration as Ventilation}

This report is concerned with recommending appropriate mechanical ventilation systems, but it is also important that we address the practice of building homes with $0.35 \mathrm{AC} / \mathrm{h}$ infiltration. In an effort to comply with ASHRAE 62 without having to install mechanical ventilation, some builders are attempting to build homes with average annual infiltration levels of $0.35 \mathrm{AC} / \mathrm{h}$. Although the standard allows infiltration to be counted toward the air-exchange rate, $0.35 \mathrm{AC} / \mathrm{h}$ infiltration cannot be relied upon to regularly ventilate homes in any climate because actual infiltration rates vary widely throughout the year so that infiltration, and in this case ventilation, is highest during winter and summer and lowest during spring and fall. Furthermore, when infiltration is the only source for air exchange in a home, there is no control over where the air is coming from (it may be from the attic or crawlspace) or how evenly the air is distributed. Because infiltration is uncontrollable and highly variable, it is not a substitute for ventilation (ESB 1995a, Smith 1994, White 1996).

We used RESVENT to estimate the number of days that homes with $0.35 \mathrm{AC} / \mathrm{h}$ average annual infiltration receive less than $0.35 \mathrm{AC} / \mathrm{h}$ average daily ventilation. The results in Table $\mathrm{D}-1$ below indicate that homes in hot climates with $0.35 \mathrm{AC} / \mathrm{h}$ infiltration would be underventilated most of the year (219-230 days); even in cold climates where infiltration-driving forces are stronger, homes would be underventilated about one-fourth of the year. Put another way, in order for infiltration to provide $0.35 \mathrm{AC} / \mathrm{h}$ on a regular or daily basis, the average annual infiltration rate would need to be considerably higher than $0.35 \mathrm{AC} / \mathrm{h}$. This finding supports the argument that $0.35 \mathrm{AC} / \mathrm{h}$ infiltration is not an effective alternative to mechanical ventilation for maintaining indoor air quality in new homes (Feustel et al. 1987, Lstiburek 1995).

Table D-1. Frequency of Under-Ventilation

in homes with $0.35 \mathrm{AC} / \mathrm{h}$ infiltration only (i.e., no mechanical ventilation)

\begin{tabular}{|lcccc|}
\hline & Boston & Wash DC & Houston & Phoenix \\
\hline days/year the home receives $<0.35 \mathrm{AC} / \mathrm{h}$ & 88 days & 102 days & 230 days & 219 days \\
$\%$ of days the home is under-ventilated & $24 \%$ & $28 \%$ & $63 \%$ & $60 \%$ \\
\hline
\end{tabular}




\section{Appendix E. Dehumidification of Ventilation Air}

Indoor relative humidity (RH) should be kept between $40 \%$ and $60 \%$; higher $\mathrm{RH}$ can lead to condensation on surfaces and favor the growth of microorganisms; lower $\mathrm{RH}$ can cause static electricity and dry nasal passages; the latter increases occupant susceptibility to infection. An average family of four contributes at least 2 gallons $(7.6 \mathrm{~kg}$ ) of water to home indoor air each day, and basements and crawlspaces contribute up to 8 gallons $(30 \mathrm{~kg})$ of water each day (Barringer 1989, Bower 1995). Spot exhaust fans in the bathrooms and kitchen should be used to remove excess moisture from those rooms, and air conditioners (if present) usually handle the residual internal latent loads. When air conditioning is absent or inadequate (e.g., in northern homes with basements during the summer), portable dehumidifiers are often employed to control humidity in part of a house.

Most new U.S. homes have central air-conditioning, and a growing number have mechanical ventilation systems, which introduce additional, external, sensible and latent loads to the home (compared to the same home without a ventilation system). In mechanically ventilated homes, it is important that contractors include ventilation loads in Manual $\mathrm{J}$ calculations for each house, use Manual $S$ to select right-sized equipment, and follow manufacturer installation instructions. Even so, dehumidification is often needed when sensible cooling is not, i.e., the latent capacity of air-conditioners is only available when the thermostat indicates a need for sensible cooling.

Because dehumidification of ventilation air is often important for occupant health and comfort, we examined the options available for controlling moisture introduced by ventilation systems. These strategies include air-conditioning, whole-house dehumidifying supply ventilation units, and energy-recovery ventilation units that transfer latent and sensible heat between air streams.

\section{E.1. Ventilation Latent Loads}

An article in the Nov 97 ASHRAE Journal proposes the use of a ventilation load index (VLI) to help HVAC professionals appreciate and anticipate latent loads attributable to active ventilation. VLI is defined as "the load generated by one cubic foot per minute of fresh air brought from the weather to space-neutral conditions $\left(75^{\circ} \mathrm{F}\left(24^{\circ} \mathrm{C}\right)\right.$ and $50 \% \mathrm{RH}(65$ grains/lb)) over the course of one year." (Of course, ventilation latent loads are concentrated during the cooling season, not evenly distributed throughout the year.) VLI varies by geographic location and consists of two numbers indicating latent and sensible loads, respectively; e.g., a VLI of " $4.0+$ 1.0 " indicates an annual latent load of 4.0 and annual sensible load of 1.0 , in ton-hours per cfm of ventilation. Table E-1 shows ventilation loads in our four cities (we use Baltimore's VLI for Washington). VLI values in Table 10 are based on TMY2 weather data (Harriman et al. 1997).

Table E-1. Latent and Sensible Loads of Ventilation Air

\begin{tabular}{|c|r|r|r|r|}
\cline { 2 - 5 } \multicolumn{1}{c|}{} & \multicolumn{1}{c|}{ Boston } & \multicolumn{1}{c|}{ Baltimore } & \multicolumn{1}{c|}{ Houston } & \multicolumn{1}{c|}{ Phoenix } \\
\hline Ventilation Load Index (VLI) & $2.0+0.3$ & $4.7+0.8$ & $13.3+2.1$ & $1.3+5.0$ \\
\hline latent load (in ton-hrs per cfm per year) & 2.0 & 4.7 & 13.3 & 1.3 \\
\hline sensible load (in ton-hrs per cfm per year) & 0.3 & 0.8 & 2.1 & 5.0 \\
\hline total load (in ton-hours per cfm per year) & 2.3 & 5.5 & 15.4 & 6.3 \\
\hline $\begin{array}{c}\text { Sensible Heat Ratio (SHR) } \\
\text { sensible load } \div \text { total load }\end{array}$ & & & & \\
\hline
\end{tabular}




\section{E.2. Air Conditioning}

The latent (moisture removal) capacity of air-conditioners is indicated by their Sensible Heat Ratio (SHR), which ranges from 61\%-78\% (Godwin 1998). To compare equipment latent capacity with the latent load of ventilation air, we converted each city's VLI to an SHR:

Air conditioner $S H R=$ sensible cooling capacity $\div$ total cooling capacity

Ventilation air $S H R=$ ventilation air sensible load $\div$ ventilation air total load

The last row of Table E-1 shows the SHR of ventilation air in each of our representative cities. Notice that, except for Phoenix, the SHR of the ventilation load in the selected cities is $13-14 \%$. In other words, $86-87 \%$ of the ventilation load is moisture, but only $22-39 \%$ of air conditioner capacity is devoted to moisture removal. Of course, in homes with mechanical ventilation, what the air conditioner encounters is not the latent load of outdoor (ventilation) air, but a mixture of outdoor air (e.g., $100 \mathrm{cfm}$ ) and indoor air (e.g., 1,000 cfm), and the latent load of this mixture varies throughout the year (Harriman et al. 1997, Kittler 1996, Shirey 1996)

The ability of cooling equipment to accommodate ventilation latent loads is determined by the way the equipment is manufactured, selected, installed, and controlled. The component that makes moisture removal possible is the evaporator coil, and the properties of an evaporator coil that affect equipment latent capacity are surface area, coil temperature, and rate of airflow across the coil. For the most part, these properties are controlled by manufacturers, whose specifications are designed to raise seasonal energy-efficiency (SEER) and coefficient-ofperformance (COP) ratings. However, specifications that improve equipment efficiency can (but do not necessarily) also reduce latent capacity (Godwin 1998, Kittler 1996) .

Residential contractors inadvertently but routinely impair manufacturer-rated latent capacity by improper sizing, selection, and installation of cooling equipment. The sensible and latent load for each house should be calculated according to Manual J, which accounts for external loads of ventilation air. Unfortunately, contractors frequently determine loads by comparison, rulesof-thumb, or other inaccurate means, and then oversize equipment to compensate for poor design, installation, and efficiency of forced-air distribution systems. However, oversized cooling equipment cannot achieve its manufacturer-rated efficiency or latent capacity because it operates more often at part-load (frequent cycling) than steady-state (optimal) efficiency. Furthermore, common mistakes such as improper refrigerant charge, mismatched indoor and outdoor coils, and improper airflow across coils further reduce efficiency and latent capacity (Davis 1998b, EDU 1997b, Proctor et al. 1995, Shirey 1996).

To optimize the ability of cooling equipment to accommodate the latent load of ventilation air in homes with mechanical ventilation, residential contractors should:

- use Manual J to calculate loads, including ventilation, for each house (ACCA 1995a),

- use Manual S to identify and select right-sized equipment (ACCA 1992),

- follow manufacturer installation instructions, including proper refrigerant charge,

- reduce airflow across the evaporator coil, within manufacturer-specified ranges,

- design, install, and verify airtight duct systems according to Manual D (ACCA 1995a),

- use a variable-speed forced-air fan that can operate at a lower speed ( $<400 \mathrm{cfm} / \mathrm{ton}$ ) when dehumidification is needed (Gehring 1994, Godwin 1998).

If air-conditioning is absent or inadequate, or if ventilation latent loads do not coincide with sensible cooling loads, another means of controlling ventilation latent loads may be needed. Air conditioners remove moisture from air after ventilation air mixes with recirculated indoor air; other options for dehumidifying ventilation air remove moisture from incoming air before it mixes with indoor air. Because the volume of ventilation air is about $10 \%$ of the volume of recirculated indoor air, dehumidification of ventilation air as it enters the home (before it mixes with indoor air) requires smaller equipment, and can therefore be more efficient. It also allows dehumidification of ventilation air when cooling is not otherwise needed (Kittler 1996). 


\section{E.3. Dehumidifying Supply Ventilation}

Because supply fans can push air through the condensing coil of a dehumidifier, a ventilation air dehumidifier can be integrated with any multi-port or forced-air supply ventilation system. Dehumidifiers are similar to air conditioners except they are designed to reduce latent, not sensible heat. They are controlled by dehumidistats, not thermostats. and typically provide no net cooling; in fact, heat generated by the compressor and latent heat removal process (condensation) increases the sensible indoor load. Portable or 'room' dehumidifiers (which cost \$200-300 each) control moisture in one area (e.g., a basement), but do not have the capacity to control the humidity of an entire house. In this report, whole-house dehumidifiers are called dehumidifying supply ventilation units, DSVUs; they include a supply fan, air filter, evaporator coil, condenser coil, and dehumidistat. Ventilation air is continuously filtered, mixed with recirculated indoor air, and distributed through ventilation-only or forced-air ductwork; incoming air is dehumidified as necessary, according to the adjustable dehumidistat. The DSVU supply fan becomes the ventilation fan; with multi-port supply, the DSVU fan replaces the supply ventilation fan, and with forced-air supply, the DSVU fan operates continuously, independently of the forced-air fan (EDU 1996a, Kittler 1996).

A DSVU increases supply ventilation installation cost by about $\$ 1000$, and requires extra space; however, DSVUs do not need to be installed during construction; they can be added any time. DSVUs with a moisture removal capacity of about $5 \mathrm{lbs} / \mathrm{hr}$ at $60^{\circ} \mathrm{F}$ and $80 \%$ outdoor RH (to a maximum 100 pints/day or $8.3 \mathrm{lbs} / \mathrm{hr}$ ) are currently the most efficient residential dehumidifiers on the market. DSVUs increase ventilation operating costs by approximately $\$ 40$ each month that dehumidification is used (EDU 1995c, EDU 1996b, Gehring 1996).

The advantage of incorporating a DSVU into supply ventilation systems is that the dehumidistat can be set to operate the dehumidifier when indoor relative humidity exceeds a certain point, e.g. 50\% RH; in other words, a DSVU can control humidity within a relatively precise range. The disadvantage of a DSVU is that ventilation system installation and operating costs increase.

\section{E.4. Energy-Recovery Ventilation}

Energy-recovery ventilators (ERVs) are balanced ventilation systems that transfer latent heat (moisture) as well as sensible heat between incoming and outgoing air streams. ERVs are not dehumidifiers; they simply transfer moisture from the more humid to the less humid air stream until equilibrium (of moisture in the air streams) or ERV moisture transfer capacity is reached. When outdoor air is more humid than indoor air, ERVs transfer moisture from the incoming to the outgoing air stream, in effect dehumidifying incoming air; when indoor air is more humid, ERVs transfer moisture from exhaust air stream to supply air streams, in effect humidifying incoming air. ERVs can reduce ventilation latent loads when outdoor air is relatively humid (e.g., in summer) and retain indoor humidity when outdoor air is relatively dry (e.g., in winter). However, unlike a dehumidifier, neither the amount nor the direction of ERV moisture transfer can be controlled. Unlike HRVs, ERVs should not be connected to bathroom or laundry exhaust; excess moisture from these rooms should be exhausted from the house, not transferred to incoming air (Barringer 1989, Davis 1998a, EDU 1995b, Steege 1998).

ERVs that are most efficient at moisture transfer are those with a desiccant-coated rotary core, which can transfer up to $80 \%$ of the difference in moisture between the two air streams. For example, if incoming air contains 120 grains moisture per $\mathrm{lb}$ of air and exhaust air contains 70 grains $/ 1 b$, the ERV can transfer $(0.80 \times(120-70)=) 40$ grains from the supply to the exhaust air stream. ${ }^{16}$ The Home Ventilating Institute (HVI) independently measures, certifies and publishes HRV and ERV performance-related parameters, including sensible recovery efficiency, latent recovery (moisture transfer), and total recovery efficiency (TRE). ERVs

16 One grain equals 0.0648 grams, or $1 / 7,000 \mathrm{lb}$. 
should be selected according to the HVI values; high latent recovery values indicate effective moisture transfer. One advantage of using an ERV instead of a DSVU is that ERVs transfer moisture passively, so there is no additional operating cost associated with ERV moisture transfer. Also, the DSVU installation cost $(\sim \$ 1,000)$ is in addition to a supply ventilation system, while ERV installation cost $(-\$ 1,400)$ is instead of a supply ventilation system (EDU 1995b, HVI 1998).

When properly manufactured, selected, installed, and controlled, ERVs remove moisture from ventilation air during the cooling season, retain indoor moisture during the heating season, and moderate changes in indoor relative humidity. However, a recent study identified numerous problems associated with ERV manufacture, selection, and installation. Five ERVs from three manufacturers were field-tested as installed in actual homes in North Carolina under conditions of relatively high outdoor RH; one model was also tested under laboratory conditions. Of four homes whose ERVs were functioning, three were tested for indoor RH before and during ERV operation; ERV operation elevated indoor RH in all three homes during testing. One of these was attributed to poor equipment selection, poor design and wiring of controls, ERV integration with compressor cooling, and exhausting of air from bathrooms and a laundry room; another was attributed to imbalanced airflows (supply cfm was $42 \%$ higher than exhaust $\mathrm{cfm}$ ) and an interlock between the air handler and wet coil. However, lack of installation problems in the third home suggested, and lab testing confirmed, that the ERV's ability to reject outdoor moisture was compromised because actual airflows were much higher than specified by the manufacturer. According to the author, "Some (balanced ventilation system problems) were manufacturing problems that caused high airflow that in turn reduced the equipment's performance-and increased indoor latent load." In each case cited, indoor relative humidity increased by a few percent during ERV operation, but did not exceed 60\% (Davis 1998a).

Although ERVs offer potential for reducing the latent load of ventilation air in some climates, their complexity and the problems described above suggest they may not yet be suitable for the production home market. As with HRVs, production homebuilders who offer ERVs as an option should consult closely with the ERV manufacturer during the home design process, and consider hiring an ERV subcontractor who commissions each system as part of the installation. 


\section{Acknowledgments}

We appreciate the funding and support of Jeanne Briskin, Sam Rashkin, Glenn Chinery, and David Lee of the EPA ENERGY STAR Homes Program. Special thanks to Jon Koomey (LBNL), without whom this report would not have been possible, and Don Stevens (Stevens \& Associates, Keyport WA) for sharing his invaluable experience and providing a crucial technical review. Thanks to Jeff Warner (LBNL) for managing the DOE-2 analysis and RESVENT quality control. Thanks also to Nan Wishner of LBNL for editorial support, Karl Brown of the California Institute for Energy Efficiency for technical critique and access to ventilation cost survey data, and John Bower of the Healthy House Institute for timely publication of his excellent book Understanding Ventilation. Thanks to Greg Rosenquist, Ian Walker, Doug Sullivan, and Woody Delp of LBNL and Danny Parker of FSEC for their engineering input. Joe Huang (LBNL) provided climate data and Nance Matson (LBNL) did RESVENT modeling.

We thank our reviewers (in alphabetical order): Steve Bodzin (Home Energy magazine), Terry Brennan (Camroden Associates), Bruce Davis (Advanced Energy), Rick Diamond and Bill Fisk (LBNL), Doug Garrett (City of Austin TX), Rob Hammon (ConSol), Joe Lstiburek (Building Science Corp), Mike Lubliner (WSU Energy Program), Frank Mayberry (Comfort Home), Gary Nelson (The Energy Conservatory), Max Sherman (LBNL), Greg Thomas (Greg Thomas Associates), Ike Turiel (LBNL), and Jim White (Canada Mortgage and Housing Corporation).

We appreciate the cooperation of equipment manufacturers and distributors who provided cost and performance information, including: Bede Wellford (Airxchange); Dennis Dietz and Dwight Shackleford (American Aldes); George Ebner and Dave Wolbrink (Broan); Gene Mills and Gary Weaver (Carrier Residential); Ken Gehring, Bernie Middlestadt, and Larry Carlson (DEC-Thermastor); Gary Churchsmith, Bradley Steele, and John O'Connell (Energy Federation Inc); Lawrin Ellis (FanTech); Armin Rudd (FSEC); Bill Archer and Lou Sulfsted (General Electric); Doug Steege (Mitsubishi Electric Air Tech America); Dave MacClellan and Paul Raymer (Tamarack Technologies); and the folks at E. B. Ward in South San Francisco.

The work described in this paper was supported by the U.S. Environmental Protection Agency, Office of Air and Radiation, Atmospheric Pollution Prevention Division through the U.S. Department of Energy under Contract No. DE-AC03-76SF00098. 


\section{References}

ACCA. 1992. Manual S: Residential Equipment Selection. Air Conditioning Contractors of America, Washington DC.

ACCA. 1995a. Manual D: Residential Duct Systems. Air Conditioning Contractors of America, Washington DC.

ACCA. 1995b. Manual J: Load Calculation for Residential Winter and Summer Air Conditioning. Air Conditioning Contractors of America, Washington DC.

American Lung Association, U S Environmental Protection Agency, Consumer Product Safety Commission, and American Medical Association. 1994. Indoor Air Pollution: An Introduction for Health Professionals. USGPO 1994-523-217/81322.

Archer, Bill, General Electric. 1998. Personal Communication. March 13.

ASHRAE. 1989. Ventilation for Acceptable Indoor Air Quality. American Society of Heating, Refrigerating and Air-Conditioning Engineers. ASHRAE 62-1989.

ASHRAE. 1993. A Method of Determining Air Change Rates in Detached Dwellings. American Society of Heating, Refrigerating and Air Conditioning Engineers. ANSIASHRAE 136-1993.

ASHRAE. 1997. Fundamentals: Chapter 25 Ventilation and Infiltration. Atlanta GA, American Society of Heating Refrigerating and Air Conditioning Engineers.

Barringer, C.G. 1989. "Effect of Residential Air-to-Air Heat and Moisture Exchangers on Indoor Humidity." ASHRAE Transactions. 95: 2, p 461-474.

Birdsall, B. et al. 1990. Overview of the DOE-2 Building Energy Analysis Program, Version 2.1D. Lawrence Berkeley Laboratory. LBL-19735.

Bower, John. 1995. Understanding Ventilation. The Healthy House Institute, Bloomington IN. 428 pp.

Bower, John. 1996. "Nine Steps to Ventilation System Design." Journal of Light Construction. 14: 2 , p 60-63.

Brennan, Terry, Camroden Associates. 1998. Personal Communication. Aug 7.

Brook, David. 1996. "Putting Pressure on Building Codes". Home Energy. Sep/Oct, p 39-43.

Cameron, Laurie. 1997. "More on Control Strategies for Exhaust-Only Ventilation." Energy Design Update. Cutter Information Corp. Nov, p 6.

Chen, Paulina, EPA Indoor Environment Program. 1998. Personal Communication. June 27.

Cummings, James B., and Neil Moyer. 1995. Reassessment of Airtightness Practices in the Florida Energy Code. Florida Solar Energy Center. FSEC-CR-793-95.

Davis, Bruce E. 1998a. "Mechanical Ventilation in Houses in the Southeast, Doing the Right Thing Not-Quite-Right". Proceedings of American Council for an Energy-Efficient Economy. Vol. 1, p 53-66.

Davis, Bruce E., Advanced Energy. 1998b. Personal Communication. June 23. 
Dietz, Dennis, American Aldes. 1998. Personal Communication. June 18.

Dumont, R.S., and J.T. Makohon. 1997. "Characterization of Volatile Organic Emissions from Building Materials for Indoor Environment Assessrnent." Energy Efficient Building Association News. Winter/Spring, p 12-17.

EDU. 1993a. "Fans for Central Exhaust Ventilation Systems." Energy Design Update. Cutter Information Corp. April, p 7-12.

EDU. 1993b. "The Ventilation Rate Myth." Energy Design Update. Cutter Information Corp. Sept, p 9-10.

EDU. 1995a. "Dual-Stage Gas Furnaces for Enhanced Humidity Control and Efficient Air Circulation." Energy Design Update. Cutter Information Corp. August, p 13-15.

EDU. 1995b. "Heat and Humidity Recovery Ventilators for Winter and Summer." Energy Design Update. Cutter Information Corp. August, p 9-12.

EDU. 1995c. "Highest-Efficiency Dehumidifier and Best (?) Ventilator for Humid Climates." Energy Design Update. Cutter Information Corp. Jan, p 8-9.

EDU. 1996a. "The Most Sensible (and Latent) Cooling System." Energy Design Update. Cutter Information Corp. Nov, p 13-15.

EDU. 1996b. "The Ultimate Central Air Purifier/Dehumidifier." Energy Design Update. Cutter Information Corp. July, p 12-13.

EDU. 1996c. "Ventilation Equipment Manufacturers Look to Southern Markets." Energy Design Update. Cutter Information Corp. Feb, p 1-2.

EDU. 1997a. "The Effectiveness of Simple Ventilation." Energy Design Update. Cutter Information Corp. Feb, p 12-13.

EDU. 1997b. "New AC Design Keeps Its Efficiency at High Temperatures." Energy Design Update. Cutter Information Corp. Oct, p 9-11.

EDU. 1997c. "Study Links Low-Level CO Exposure to Brain Damage." Energy Design Update. Cutter Information Corp. Nov, p 3.

EDU. 1998. "New Aldes Fan Has Power and Versatility." Energy Design Update. Cutter Information Corp. March, p 16.

ESB. 1995a. "Build Tight, Ventilate Right." Originally published in Energy Source Builder. Iris Communications, Inc. http://solstice.crest.org/efficiency.

ESB. 1995b. "Home Ventilation Options for Home Builders." Originally published in Energy Source Builder. Iris Communications, Inc. http://solstice.crest.org/efficiency/iris.

Feustel, Helmut E., Mark P. Modera, and Arthur H. Rosenfeld. 1987. Ventilation Strategies for Different Climates. Lawrence Berkeley Laboratory. LBL-20364.

Finley, Scott. 1997. "Using Diagnostic Tools to Improve Indoor Air Quality". Home Energy. Nov/Dec, p 15-19.

Fisk, William J., and Isaac Turiel. 1983. "Residential Air-to-Air Heat Exchangers: Performance, Energy Savings, and Economics." Energy and Buildings. 5: 3, p 197-211. 
Gehring, Kenneth C. 1994. "Ventilation and Humidity Control Of A Home In A Humid Climate". Proceedings of Energy Efficient Building Association. Vol. B, p 34-48.

Gehring, Kenneth C. 1996. "Humidity Control - A Critical Component of a Healthy Home". Proceedings of Energy Efficient Building Association. Vol. 13, p 1-4.

Gehring, Kenneth C., DEC Thermastor. 1998. Personal Communication. May.

Godwin, David S. 1998. "Latent Capacity of Unitary Equipment." ASHRAE Transactions. 104: 2,

Greiner, Thomas H. 1997. "Carbon Monoxide Problems from New Furnaces". Home Energy. May/June, p 19-23.

Harriman, Lewis, D. Plager, and D. Kosar. 1997. "Dehumidification and Cooling Loads from Ventilation Air." ASHRAE Journal. 39: 11, p 37-45.

Hekmat, D., H. E. Feustel, and M. P. Modera. 1986. "Impacts of Ventilation Strategies on Energy Consumption and Indoor Air Quality in Single-family Residences." Energy and Buildings. 9: p 239-251.

Hodgson, A.T. 1997. "Indoor Air Quality in New Energy-Efficient Houses." Center for Building Science News. Spring 1997, p 6-7.

HVI. 1998. Certified Home Ventilating Products Directory. Home Ventilating Institute. HVI911.

Jackson, Mark A. 1993. "Integrated Heating and Ventilation: Double Duty for Ducts". Home Energy. May/June, p 27-33.

Kesselring, John. 1991. "Measuring and Modeling Residential Infiltration". EPRI Journal. Jul/Aug, p 41-44.

Kittler, Reinhold. 1996. "Mechanical Dehumidification Control Strategies and Psychrometrics." ASHRAE Transactions. 102: 2, p 613-617.

L'Ecuyer, Michael, Cathy Zoi, and John S. Hoffman. 1993. Space Conditioning: The Next Frontier. USEPA Office of Air and Radiation, Washington DC.

Lstiburek, Joseph W. 1995. Air Distribution for the Exemplary Home. Alternative Energy Corporation, Research Triangle Park NC. $72 \mathrm{pp}$.

Lubliner, Michael, Washington State University Energy Program. 1998. Personal Communication. October.

Lubliner, Michael, Don T. Stevens, and Bob Davis. 1997. "Mechanical Ventilation in HUD-Code Manufactured Housing in the Pacific Northwest." ASHRAE Transactions. 103: 1, p 693-705.

Marion, W., and K. Urban. 1995. User's Manual for TMY2s. National Renewable Energy Laboratory, Golden CO.

Matson, N.E., and H.E. Feustel. 1998. Residential Ventilation System: Final Report. NYSERDA. LBNL-40857.

Means, R.S. 1997. Mechanical Cost Data. R.S. Means Co., Inc., Kingston MA. 567 pp.

Mills, Gene, Carrier Residential. 1996. Personal Communication. August. 
Nelson, Gary, The Energy Conservatory. 1998. Personal Communication. May 26.

Palmiter, Larry S. 1991. "Measured Infiltration and Ventilation in 472 All-Electric Homes." ASHRAE Transactions. 97: 2, p 979-987.

Palmiter, Larry S., and Ian Brown. 1989. Northwest Residential Ventilation Survey: Analysis and Results. Washington State Energy Office.

Proctor, John, Zinoviy Katsnelson, and Brad Wilson. 1995. "Bigger is Not Better: Sizing Air Conditioners Properly". Home Energy. May/June, p 19-26.

Rashkin, Sam, and Lisa Bloomfield-Resch. 1997. "EPA's ENERGY STAR Homes Program Breaking the Myth That Energy Efficient Homes Cost More!" EEBA News. Energy Efficient Building Association. Spring, p 20-22.

Reardon, James T. 1995. Ventilation Systems for New and Existing Houses with Baseboard Heating. Canadian Electrical Association. CEA 9229 U 967.

Rudd, Armin F. 1998a. "Design/Sizing Methodology and Economic Evaluation of Central-FanIntegrated Supply Ventilation Systems". Proceedings of American Council for an EnergyEfficient Economy. Vol. 1, p 299-313.

Rudd, Armin F., Florida Solar Energy Center. 1998b. Personal Communication. August 19.

Sherman, M.H., and N. Matson. 1996. Residential Ventilation and Energy Characteristics. Lawrence Berkeley National Laboratory. LBNL-39036.

Sherman, M.H., and D.J. Wilson. 1986. Relating Actual and Effective Ventilation in Determining Indoor Air Quality. Lawrence Berkeley Laboratory. LBL-20424.

Shirey, Don B. 1996. "Impacts of ASHRAE Standard 62-1989 on Small Florida Offices." ASHRAE Transactions. 102: 2,

Smith, Bill Rock. 1994. "Heat Recovery Ventilators." Journal of Light Construction. 12: 6, p 31-36.

State of Washington. 1998. Ventilation and Indoor Air Quality Code. Olympia WA.

Steege, Doug, Mitsubishi Electric Air Tech America, Inc. 1998. Personal Communication. Sept 22.

Stevens, Don T. 1996. "Mechanical Ventilation for the Home". Home Energy. Mar/Apr, p 13-19.

Tsongas, George. 1993. "Building Tightness Guidelines: When Is a House Too Tight?". Home Energy. Mar/Apr, p 18-24.

Ulness, Amy. 1997. "Healthy Choices". Builder. Jan, p 338-342.

White, Jim H. 1996. "Ventilate Right, Then Build Tight". Home Energy. Nov/Dec, p 4.

White, Jim H., Canada Mortgage and Housing Corporation. 1998. Personal Communication. June 8.

Wilber, Matt, and Marilou Cheple. 1997. "The Carbon Monoxide Connection." EEBA News. Energy Efficient Building Association. Spring, p 18-19. 